TI 2018-060/V

Tinbergen Institute Discussion Paper

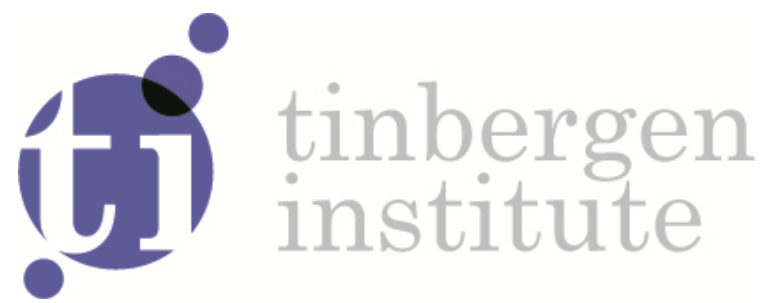

\title{
Better off at home? Effects of a nursing home admission on costs, hospitalizations and survival
}

\author{
Pieter Bakx ${ }^{1}$ \\ Bram Wouterse ${ }^{2}$ \\ Eddy (E.K.A.) van Doorslaer ${ }^{3}$ \\ Albert Wong ${ }^{4}$
}

1: Erasmus School of Health policy and Management, Erasmus University Rotterdam

2: CPB Netherlands Bureau for Economic Policy Analysis, The Hague

3: Erasmus School of Economics Rotterdam; Tinbergen Institute, The Netherlands

4: RIVM National Institute for Public Health and the Environment, the Netherlands 
Tinbergen Institute is the graduate school and research institute in economics of Erasmus University Rotterdam, the University of Amsterdam and VU University Amsterdam.

Contact: discussionpapers@tinbergen.nl

More TI discussion papers can be downloaded at the Tinbergen Site

Tinbergen Institute has two locations:

Tinbergen Institute Amsterdam

Gustav Mahlerplein 117

1082 MS Amsterdam

The Netherlands

Tel.: +31(0)20 5984580

Tinbergen Institute Rotterdam

Burg. Oudlaan 50

3062 PA Rotterdam

The Netherlands

Tel.: +31(0)10408 8900 


\title{
Better off at home?
}

\section{Effects of a nursing home admission on costs, hospitalizations and survival}

\author{
Pieter Bakx ${ }^{\mathrm{a}, \mathrm{b}, *}$, Bram Wouterse ${ }^{\mathrm{a}, \mathrm{b}, \mathrm{c}}$ Eddy van Doorslaer $^{\mathrm{a}, \mathrm{b}, \mathrm{d}, \mathrm{e}}$, Albert Wong ${ }^{\mathrm{b}, \mathrm{f}}$
}

\begin{abstract}
Aging-in-place policies substitute home care for nursing home admissions (NHA). They appear to be a win-win by keeping public spending in check and being in line with personal preferences, but have hitherto not been evaluated. We study the impact of NHA eligibility using Dutch administrative data and exploiting variation between randomly assigned assessors in their tendency to grant admission. The impact on mortality is zero, but with considerable effect heterogeneity. Moreover, aging-in-place policies come at the cost of increased curative care, especially hospital admissions, and do not reduce total healthcare spending, suggesting they may not be a win-win after all.
\end{abstract}

JEL Codes: C26, I10

Keywords: long-term care, policy evaluation, instrumental variables

\footnotetext{
${ }^{a}$ Erasmus School of Health Policy and Management, the Netherlands, ${ }^{\mathrm{b}}$ Network for Studies on Pensions, Ageing and Retirement, the Netherlands, " CPB Netherlands Bureau for Economic Policy Analysis, the Netherlands ${ }^{\mathrm{d}}$ Erasmus School of Economics, Erasmus University Rotterdam, the Netherlands, ${ }^{\mathrm{e}}$ Tinbergen Institute, the Netherlands, ${ }^{\mathrm{f}}$ RIVM National Institute for Public Health and the Environment, the Netherlands. * Corresponding author; e-mail address: bakx@eshpm.eur.nl.

This research is funded by RIVM's Strategic Research Program (project number S/210001) and uses non-public data available at Statistics Netherlands. We thank Statistics Netherlands and CIZ for granting access to data. We are also grateful to Jonneke Bolhaar, Denise Doiron, Itzik Fadlon, Raf van Gestel, Hans van Kippersluis, BartWillem Lenders, Francesco Moscone, Owen O’Donnell, Johan Polder, Rikkert Smith and seminar participants at the Australasian Workshop on Health Econometrics and Economics, CentER, CPB, CEPRA/NBER Conference on Aging and Health, Dutch Economists' Day 2017, iHEA 2017 World Congress, Lowlands Health Economics Study Group 2017, Netspar workshop on LTC: reforms and redistribution, and RWI Essen for comments on earlier versions of this paper.
} 


\section{Introduction}

The rising costs of long-term care (LTC) are a major public policy concern. Aging-in-place policies, aimed at postponing nursing home admissions (NHA), are popular and seen as an effective way to contain LTC costs (Guo et al. 2015). Since the 1980s, a shift from nursing home care towards home care has taken place in the United States (US) (Bishop 1999; McKnight 2006) and other developed countries. Among the Organization for Economic Cooperation and Development (OECD) countries, the average share of elderly LTC recipients receiving care at home increased from 59 percent in 2000 to 65 percent in 2013 (OECD 2015). Aging in place is often argued to be a win-win: it keeps costs down by substituting cheaper home care for more expensive nursing home care, and it is in line with preferences of the elderly, whose satisfaction and quality of life are believed to be higher at home than in a nursing home (OECD 2011, 2015; Guo et al. 2015; Kim and Lim 2015).

Admitting a frail, old person to a nursing home affects his/her health in multiple, possibly offsetting, ways. On the one hand, nursing homes provide a protective environment with round-the-clock care, and are thus expected to have a positive influence on their residents' health. On the other hand, a NHA may also be detrimental to health, because the transition to a nursing home is a major, often irreversible and disruptive, life event and because nursing homes probably provide a lower-quality life environment. Finally, nursing homes are "total institutions” (Goffman 2009) that take over many aspects of the everyday life of residents. This may lead to passivity and dependence, and a (perceived) partial loss of control and of one's identity.

Healthcare spending may also rise or fall following a NHA: a NHA is expensive because of facility costs, living $\operatorname{costs}^{1}$ and the intensity of care provided. Yet, a NHA may be cheaper if keeping patients at home requires intensive care that can be provided more efficiently in

\footnotetext{
${ }^{1}$ In The Netherlands, the rent and cost of living in a nursing home are also covered by public LTC insurance.
} 
nursing homes, due to economies of scale. Moreover, a NHA may reduce spending on medical care, because the nursing home staff takes over tasks from other providers, or the care that is provided may prevent accidents warranting a doctor visit or hospitalization.

Evidence on the effects of aging-in-place policies on NHAs and healthcare spending is scarce, however. Kim and Lim (2015) use cut-offs in the design of public LTC insurance benefits in South Korea, which include a threshold that elderly with the most severe limitations to choose home care over an NHA. For this group, the regression discontinuity shows that increased home care spending decreased medical expenditures but had no significant impact on total LTC spending and on informal care use. ${ }^{2}$ Further evidence is limited to the evaluation of expansions (see e.g. Marek et al. 2012; Weissert and Frederick 2013; Guo et al. 2015) and a reduction (McKnight 2006) of home care subsidization in the US. The latter set of studies focuses on whether subsidizing home care affects nursing home care use and costs, yet do not address the question of what the net health and cost effects of actual substitution are. The main reason that the net health effect of a NHA has not been studied before is that individuals self-select - patients who receive institutional care are usually in worse health than those who continue to live at home - and therefore these groups cannot be compared directly ${ }^{3}$.

To address this selection problem, we exploit two institutional features of LTC organization in The Netherlands. First, virtually all LTC is paid for through the public LTC insurance scheme (94 percent of total public LTC expenditures, including all spending on nursing home care) or the Social Support Act (6 percent) (CBS 2016). Second, to become eligible for publicly funded LTC, patients need to request an assessment from an independent

\footnotetext{
${ }^{2}$ The difference-in-differences analyses that are done as robustness checks reconfirm the zero effect on informal care but shows a positive impact on LTC spending and no effect on medical spending (Kim and Lim 2015).

${ }^{3}$ There are some studies that do investigate differences in health and costs between home care and nursing home care users, but they rely on observed characteristics to control for differences between the two groups (e.g. Chappell et al. (2004). A study done in The Netherlands, which relies on propensity score matching, founnd that nursing home care is more expensive than home care (Kok et al. 2013).
} 
government agency. While the eligibility criteria are set by the Minister of Health and documented in policy guidelines, the assessors working for this agency have considerable discretionary power when deciding on an applicant’s eligibility, which we exploit as a source of random variation in the probability of becoming eligible for a NHA (see Doyle 2007; Maestas et al. 2013; French and Song 2013; Dahl et al. 2014 for applications in other settings).

Our instrumental variable estimates imply that eligibility for a NHA decreases the probability of a hospital admission but suggest there is no evidence of an effect on the mortality risk and healthcare spending. These results apply to applicants who are sufficiently close to the eligibility threshold for the leniency of the assessor to play a crucial role. As this is the prime target group of aging-in-place policies, such policies may not be saving healthcare expenditures, as generally hypothesized (cf. OECD 2011, De Meijer et al. 2015; Guo et al. 2015; Kim and Lim 2015).

\section{LTC in The Netherlands}

\section{A. LTC}

LTC helps individuals to cope with functional limitations. The focus here is on LTC for the elderly - about two-thirds of all LTC recipients ${ }^{4}$ - who may need help because of limitations caused by physical deterioration often related to chronic conditions or psychogeriatric problems (e.g. dementia). There are two types of LTC: formal care, provided by paid professionals; and informal care, provided by family members, friends or neighbors. We concentrate on formal care, which is provided at home or in a nursing home.

\footnotetext{
4 The other groups receiving LTC are the mentally handicapped, the physically disabled and patients with chronic mental illnesses. Together, these groups account for about a third of all LTC users (CBS 2016).
} 
With 2.6 percent of gross domestic product (GDP) spent on public LTC provision (OECD 2017), The Netherlands has one of the most extensive public LTC systems in the world. While in most countries out-of-pocket expenditures on formal care are substantial (OECD 2011), in The Netherlands virtually all formal care, delivered at home or in institutions, is paid for by mandatory social insurance ${ }^{5}$. Co-payments are relatively low: only 8 percent of public expenditure on LTC was financed from co-payments in 2014 (CBS 2016).

Institutional care is provided in a nursing or residential care home: an environment that is adapted to the needs of frail, elderly residents ${ }^{6}$. The setting and intensity differ depending on the needs and health problems. Nursing homes provide intensive care and medical treatment to elderly with severe health and psychogeriatric problems. Patients generally stay in oneperson bedrooms. Autonomy, especially for patients with dementia, is very limited. Nursing home residents receive care ranging from 3.5 to 33.5 hours per week. In residential care homes, the focus is on providing assistance to elderly who cannot live independently. Generally, these homes have small apartments where the elderly live on their own or with their partners (Kok et al. 2015). Care, meals and day activities are provided, but the elderly still have substantial autonomy.

Home care is formal care, provided by professionals, at home. As covered by Dutch social insurance, this includes social support, personal care (assistance with washing, dressing and eating) and nursing. The quantity and intensity of care may vary considerably according to the (assessed) needs of the elderly: from one hour of personal care per week to around-theclock nursing.

An independent government agency (Centrum Indicatiestelling Zorg - CIZ) decides the level and types of care for which applicants are eligible (see Section 2.2). Individuals who are

\footnotetext{
${ }^{5}$ In addition, public provision of domestic help is funded from general taxation.

${ }^{6}$ Public financing for residential care home stays was terminated in 2013.
} 
eligible for public LTC may choose to receive this care in-kind or to receive a cash transfer amounting to about 75 percent of the value of the in-kind services. In-kind care is provided by private not-for-profit or for-profit (home care only) providers that are contracted by regional single payers. These single payers are allocated a budget based on past spending in the region. While this budget is often fully spent, waiting lists are virtually non-existent (Bakx et al. 2016a).

The government has implemented various measures since 2000 to incentivize and facilitate the postponement of NHAs. It has increased the supply of home care (from 2000); has introduced the option of receiving home care for those eligible for institutional care (2007); has increased co-payments for institutional care (2013); and, has tightened the eligibility criteria for institutional care (2014) (Alders et al. 2015; De Meijer et al. 2015).

\section{B. The assessment procedure ${ }^{7}$}

Individuals who may need LTC apply for an assessment to the regional CIZ office, or ask a healthcare provider or family member to do so on their behalf. Assessors handle one of three types of applications - for elderly care, care for the disabled or long-term mental health care - but there is no further specialization. Applications are assigned to assessors by a planner taking into account only the priority status of the application ${ }^{8}$ and assessor workload - but not any information about patient's health or care needs.

The assessor has access to: i) information filled out on the application form; ii) information about prior LTC use; and, iii) any information collected in previous applications. He/she decides which information needs to be verified or updated. The assessor may contact the

\footnotetext{
${ }^{7}$ The description of the assessment procedure is based on the rules described in CIZ (2013) and face-to-face interviews with a team coach (and former assessor) and a data manager at CIZ. This is an abridged version, the full version is in Appendix B.

${ }^{8}$ All applications must be handled within six weeks. However, some applications need to be handled within 24 or 48 hours.
} 
patient, household and family members, the health insurer, and the healthcare providers (e.g. the general practitioner [GP] or a LTC provider). The assessment framework requires the assessor to take into account the health, health-related limitations, living conditions, social environment, psychiatric and social functioning of the applicant, and any other professional services and informal care the patient is receiving. The assessor is a street-level bureaucrat (Lipsky 2010) who applies general rules to specific cases. To do this, he/she has - and needs to have - considerable discretionary power. Assessors have the freedom to determine which of the abovementioned aspects are relevant, and to determine which information is verified or collected and how this will be done.

The assessor then decides whether the applicant is eligible for nursing home care or home care and, if applicable, the type and amount of home care - nursing, personal care or assistance. If the applicant does not agree with the decision, he/she may appeal and the decision is reconsidered. The applicant appeals in less than 1percent of cases and 25 percent of these appeals are approved (CIZ 2014). The initial decision is usually only reversed because new or additional information is made available.

\section{Data}

\section{Study population and available information}

The data set consists of all eligibility applications handled by CIZ for the years 2009-2013 ${ }^{9}$ and for which full information on all covariates was available. To create a homogenous study population for which the leniency of the assessor is relevant, the population was restricted to applicants of at least 65 years of age, who applied for a permanent $\mathrm{NHA}^{10}$ indicating a

\footnotetext{
${ }^{9}$ Thus excluding assessments done by mandated providers.

${ }^{10}$ Including residential care facilities.
} 
psychogeriatric or somatic condition (thus excluding the sensory and mentally handicapped) and who were not already eligible for a NHA when they applied.

Applications made by medical specialists or hospitals on behalf of a patient were removed because in these cases the type of care requested is virtually always granted. Excluding these applications means that the results may not apply to patients experiencing major health shocks requiring hospitalization and subsequent post-acute NHA. Finally, applications were removed from the sample when the assessor handling the application was unknown or handled fewer than 50 of these applications in all the years combined. Excluding these applications does not have an effect on the generalizability of the results, as the allocation of cases to assessors is arbitrary within a region.

The eligibility data contain the eligibility decision and information on who filed the application, the type of application and whether it was part of the random 5 percent of applications that receive a full review (see Appendix B for details). These data were linked at the individual level to data on the use of LTC provided in kind (2008-2014) ${ }^{11}$; vital statistics, including death records (2009-2015), household composition (2009-2013), family composition (2009-2013) and the distance at which the children live (2009-2013, if applicable); household income and household wealth (2009-2013); hospital discharge data (2008-2012); and to annual claims data from mandatory public health insurance covering roughly two-third of spending on medical care (2009-2014). ${ }^{12}$

\footnotetext{
${ }^{11}$ Information on the use of support (begeleiding) is only available from2011 onwards.

${ }^{12}$ All these data are available for all applicants, with two exceptions. First, healthcare expenditure data are not available for individuals who are insured through a proxy holder (about 10 percent in this subpopulation); probability weights are used to correct for this. Second, discharge information is lacking for approximately 10 percent of all hospital admissions. There is regional variation in the coverage of the registration of hospital admissions and hence missing values on these variables are not random but are nonetheless not expected to affect the results because we control for the region of residence.
} 
The number of observations in the study population is 51,047 for 49,187 individuals; 3.7 percent applied twice or more, and the maximum number of applications for a NHA by an individual is four. 


\section{Descriptive statistics}

The applicants in the study population were mostly women, who were old and close to death

(Table 1, Column 1). They also used a lot of health care: medical care expenditures in the next calendar year are close to 6000 Euro, almost three times the population average (Bakx et al. 2016b). Their prescription drug use suggests a high rate of multimorbidity, e.g. cardiovascular problems (52 percent used antithrombotics in ATC category B01), infections (antibiotics in J01: 41\%) and diabetes (medication in A10: 18\%). Of the applicants 30.4 percent died within two years of the application. Finally, the majority were already eligible for home care at the time of the application and used on average about 5.4 hours of home care per week in the year prior to the application ${ }^{13}$.

Initial (non-)eligibility does not automatically result in (non-)admission. Not all of the applicants eligible for a NHA move there: after one year, only 64 percent of those eligible had done so, after two years 76 percent (Column 2). By contrast, 27.1 percent of rejected applications were admitted within a year and 44.9 percent within two years (Column 3). Eligible applicants showed higher mortality rates and lower healthcare spending (conditional on surviving until the start of the next calendar year) than non-eligible applicants. This may be due to three reasons: i) it may reflect that nursing homes are capable of keeping their residents healthier and thus their demand for health care low; ii) nursing homes provide some of the care that would otherwise be provided by general practitioners and hospitals and pay for prescription drugs; and, iii) selective mortality, i.e. the highest spending nursing home residents have the lowest probability of surviving to the end of the calendar year.

\footnotetext{
13 This figure comes from a back-of-the-envelope calculation in which we round the cost of one hour of home care to 40 Euro and use 11,297 Euro of home-care spending in the year prior to the application.
} 


\section{Empirical strategy}

\section{A. Instrumental variable (IV) analysis}

We estimated the effect of eligibility for a nursing home admission (ENHA) on an applicant's outcome $y$ (i.e. survival, healthcare use or healthcare expenditures). For a given applicant $i$, suppose that the relationship between ENHA and $y$ follows the model:

$$
y_{i}=\mathrm{x}_{i}^{T} \times \beta+\gamma \times E H N A_{i}+v_{i},
$$

where $\mathrm{x}_{i}$ is a vector containing observed characteristics, and $v_{i}$ is the independent and normally distributed error term. It is likely that assessors have more information on the applicant's health than can be gathered from the data, and that they use this in their decision. If so, $E N H A_{i}$ is likely to be correlated with unobserved health, and direct estimation of Equation (1) using an Ordinary Least Squares regression (OLS) provides a biased estimate of the effect $\gamma$ of $E N H A_{i}$ on the outcome $y_{i}$. Since applicants in poorer unobserved health are more likely to be deemed eligible for a NHA than individuals in better health, we expect an upward bias in the OLS estimates of $\gamma$ in the analyses explaining mortality and NHAs. Whether the bias for the effect on healthcare expenditures is also positive is not clear, as it depends on two additional factors: i) the degree to which a NHA substitutes for other types of care; and,ii) how differences in unobserved health affect the use of these types of care.

To eliminate the bias, we employed an instrumental variable analysis, in which we exploit the fact that $E N H A_{i}$ is partly random. The source of this randomness is that, as described above, i) an applicant's eligibility status is determined by an employee of the needs-assessment agency; ii) the allocation of cases to assessors is arbitrary within a region; and,iii) that assessors have some discretionary power, with some more likely to judge the same applicants as eligible than others, i.e. to be more lenient. Hence, whether the applicant is assessed by a more lenient assessor may be used as an instrument for $E N H A_{i}$ in the instrumental variable analysis. 
We summarized the leniency of evaluators in one measure to create a strong instrument ${ }^{14}$. Following Maestas et al. (2013), we defined leniency for application $i$ handled by assessor $j$ by taking the share of the other cases for which the assessor considered a NHA appropriate:

$$
\text { Leniency }_{i}:=\frac{\text { Number of approvals }}{\left.j-I_{i} \text { (approved }\right)}
$$

We excluded case $i$ itself to ensure that the instrument is exogenous. Assessors with greater approval shares are taken to be more lenient.

Subsequently, we adjusted the leniency measure for region-specific differences and differences in the types of applications handled ${ }^{15}$. Using this standardized estimate of Leniency $_{i}$ as an instrument, Lentency $y_{l}$, we can obtain an unbiased estimate of $\gamma$ using the following Two-Stage Least Squares regression (2SLS):

$$
\begin{gathered}
E_{\text {NHA }}=\mathrm{x}_{i}^{T} \times \theta+\lambda \times \widetilde{\text { Lenlen }} y_{\imath}+\eta_{i} \\
y_{i}=\mathrm{x}_{i}^{T} \times \beta+\gamma \times \widehat{E N H A}_{\iota}+\varepsilon_{i}
\end{gathered}
$$

where $E \widehat{N H A}_{\imath}$ in Equation (4) is the predicted probability of $E N H A_{i}$ from Equation (3).

\section{B. Interpretation}

The interpretation of the results is affected by two aspects. First, we estimated the causal effect of eligibility for a NHA, not the effect of an admission itself. Applicants who are eligible for a NHA may choose to postpone the admission or to not use any nursing home care at all, while applicants who are currently ineligible for a NHA may reapply, become

\footnotetext{
${ }^{14}$ The most straightforward way to exploit the differences between assessors would be to generate an indicator variable for each assessor and use this set of indicator variables as instruments. But this strategy would yield a large number of instruments for just one endogenous regressor. Furthermore, each of these assessor dummies separately would have a small impact on the overall probability of a NHA. As a result, this approach is expected to yield biased estimates (Wooldridge 2010, French and Song 2013, Maestas et al. 2013).

${ }^{15}$ More specifically, we use an OLS regression to correct for information about the applications, i.e. the region and the period in which the application was submitted; whether the application was filed by a) the patient, b) his family doctor, c) his LTC provider, or d) someone else (e.g. a family member); whether it was a) a regular application, b) an application that followed a temporarily valid emergency application, or c) another type of application. A robustness check in which the leniency score is not adjusted confirms that the instrument is strong (results available upon request). We prefer the adjusted leniency score for efficiency reasons.
} 
eligible and be admitted later: about half of the control group is admitted at some point in the future (Table 1, Column 2). These dynamics imply that we cannot use the current setup to study the effects of a NHA on the outcomes: even if the assignment of the eligibility decision is completely random, the uptake and timing of nursing home care may still be correlated with unobserved (changes in) health (cf. Abbring and Van den Berg 2005; Eberwein et al. 1997; Cellini et al. 2010). ${ }^{16}$

The simplest interpretation of the results is that the eligibility decision is the treatment. However, we expect differences between eligible and non-eligible applicants to be solely caused by differences in the timing and quantity of use of nursing home care ${ }^{17}$. Therefore, another interpretation is that we are estimating an intention-to-treat effect ${ }^{18}$ for nursing home care: the effect of offering individuals access to the actual treatment, i.e. a NHA.

Second, the IV analysis provides an estimate of the local average treatment effect (LATE): the average effect of eligibility for compliers, i.e. those applicants who are at the margin of eligibility and for whom the eligibility decision is affected by the assessor's leniency. Some applicants are never eligible for nursing home care, regardless of the assessor's leniency: the never takers. Others - the always takers - are always eligible for nursing home care (e.g. because of severe health limitations) even if assessed by the strictest assessor. As the compliers might have different characteristics than the always- and never-takers, and the

\footnotetext{
${ }^{16}$ Two approaches would enable using a NHA as the endogenous variable. First, following Abbring and Van den Berg (2005) a joint-duration model of admission and outcome may be estimated (see Eberwein et al. [1997]). This approach, however, requires restrictive assumptions about the distribution of the unobserved effects and preliminary analyses showed the model could not be properly identified using our data.

The second approach considers admission within an arbitrary time period $t$ after the eligibility decision as the endogenous variable and measures outcomes over a subsequent period $(t, t+x)$. Autor et al. (2015) show that, under additional monotonicity assumptions, the estimate can be interpreted as a LATE. Nonetheless, the results from this approach (available upon request) do not have straightforward interpretation because the treatment differs within the treatment group: some treated individuals are admitted right away, while others only at the end of the period $t$. Hence, it is not clear what effect is being estimated.

${ }^{17}$ It is unlikely that eligibility has a direct effect on the outcomes.

${ }^{18}$ Our approach differs from a design in which the intention to treat is used as an instrument for the treatment; this would mean using eligibility as an instrument for actual admission. Instead, we use leniency as an instrument for eligibility to obtain an unbiased estimate of the effect of eligibility not of NHA.
} 
effects of ENHA might be heterogeneous, the LATE identifies the average effects for the compliers only.

We cannot identify the compliers individually, but we can examine their group characteristics by looking at the relative likelihood of a marginal applicant having a particular characteristic relative to the full population of applicants. We did this by dividing subgroup-specific firststage coefficients for the leniency measure by the first-stage coefficient for leniency for the full population (Angrist and Pischke 2009).

Therefore we estimated the effect of access to nursing home care for individuals who are at the margin of eligibility. This seems to be one of the most policy-relevant effects. First, the way that policy makers in The Netherlands and a number of other countries often try to influence the use of nursing home care is through the eligibility decision (OECD 2011; Bakx et al. 2015). Second, such policy changes are likely to mainly affect the compliers. Aging-inplace policies often entail marginal shifts in the rate at which the elderly move to a nursing home. These changes will most likely affect the access to nursing home care for applicants at the margin of eligibility, and not for applicants with very severe health problems.

\section{Outcomes and selection of covariates}

We considered six outcomes. First and second, we looked at the effect of eligibility on NHAs and on LTC expenditures, which consist of spending on home care and nursing home care. Third and fourth, we looked at spending on medical care and the probability of having at least one hospital admission. A NHA may affect use and costs of curative care by affecting the health and survival of the admitted and through substitution: nursing homes pay for some of the medical care that would otherwise have been covered by health insurance and a nursing home might substitute for hospital care. Fifth and sixth, we estimated the impact on all-cause 
mortality and on morbidity, as measured by the hospital discharge diagnoses-based Charlson index (Sundararajan et al. 2004).

We controlled for all information available to CIZ when the application was assigned to an assessor and added information from the sources described in section III. $^{19}$ We included information on: i) the type and timing of the application; ii) prior use of LTC and health care, including detailed information on medicine use; and, iii) socio-economic and demographic characteristics, including the age, gender, region of residence, household wealth, income and household and family composition of the applicants (Table A2 in Appendix A contains a full list of covariates).

\section{Appraisal of assessor leniency as instrumental variable}

To be a good instrument, the measure of the assessors' leniency needs to fulfill three requirements: it needs to be relevant and valid, and it needs to affect the probability of an admission monotonically.

\section{Assumption 1: relevance}

The variation in the leniency of assessors that handle more than 50 cases $(n=455)$ is considerable: the share of patients that are rated as eligible for nursing home care ranges from 0.53 to 1.0 (standard deviation $=0.08$ ) across assessors. ${ }^{20}$ After adjusting for differences in

\footnotetext{
${ }^{19}$ We do not include the information on health status and functional limitations collected by the assessor. Assessors decide themselves which (additional) information they gather and may interpret situations differently. Analyses (available upon request) using detailed information on functional limitations from the Health Care Monitor survey of $2 \%$ of the population in 2012 show that more lenient assessors are more likely to overreport limitations and disabilities. Hence, including the information reported by the assessor would lead to an underestimation of the effect of assessor leniency on the probability of being eligible for a NHA and hence to overestimation of the health effects of an admission.

${ }^{20}$ Figures A.1 and A.2 in Appendix A contain histograms detailing the distribution of the caseload across the assessors and the share of applications that they approve.
} 
types of applications handled and regions, the variation is reduced (standard deviation $=0.07$ ) but between-assessor differences remain substantial (Figure 1).

The first-stage estimates presented in Table 2 confirm the relevance of the leniency instrument: the significance of the coefficient for leniency, the F-statistic and the partial $\mathrm{R}^{2}$ statistic show that assessor leniency has a strong effect on the probability of being labeled eligible for a NHA. Being assigned to a one standard deviation more lenient assessor increases the probability of receiving nursing home care by 6.8 percentage points.

\section{Assumption 2: validity}

As explained in Section C, assessors are assigned to applications by a planner whose main goals are: i) to ensure that every application is reviewed on time; and, ii) that assessors have an even workload. Applicants cannot pick an assessor and assessors cannot select which types of applications they would like to review. This means that the validity of the instrument is plausible: the assignment procedure makes it unlikely that the instrument is correlated with any (unobservable) characteristics of the applicant. ${ }^{21}$

While this claim cannot be verified empirically, we further examined its plausibility by testing whether the instrument is correlated with observed characteristics. It is more likely that none of the subgroups based on unobserved characteristics is being assessed by more lenient assessors, if none of the observed subgroups of applicants on average is assessed by a more lenient assessor ${ }^{22}$. To this end, we inspected which characteristics are correlated with assessor leniency by regressing it on the observed characteristics of the applicant (cf. French

\footnotetext{
${ }^{21}$ In addition, the arbitrary assignment of applications to assessors means that Stable Unit Treatment Value Assumption (SUTVA) holds, as it rules out serial correlation in the leniency of assessors reviewing applications made by the same applicant (or the same group or household).

${ }^{22}$ The crucial assumption is that the observed and unobserved characteristics are correlated, which is highly likely in this case because of the availability of information on all aspects influencing the health of the applicant and the probability of a NHA, including past health status, socio-economic status, informal care availability and demographic background characteristics.
} 
and Song 2013). ${ }^{23}$ Any difference between observable subgroups of applicants in the average leniency of their assessors might be a sign of non-random assignment, in particular when the difference is in a characteristic that is likely to be connected to the applicant's unobserved health. This regression reveals that when correcting for all other characteristics (and correcting for multiple testing using the method developed by Benjamini and Hochberg (1995)), there are no between-group differences in assessor leniency (Table A4 in Appendix A).

To further assess the exclusion restriction, we used results from a Least Absolute Shrinkage and Selection Operator (Lasso) analysis (see Section V.D). We used this as a robustness check to see whether our main results changed when we used automated variable selection based on all available information in our data set. As suggested by Belloni et al. (2014), we let the Lasso select the covariates for three equations: the first-stage and second-stage equations of the 2SLS estimation, and an equation explaining the leniency score. The estimation results for the leniency score equation also provide further insight into the validity of the IV: if the Lasso does not select any (health-related) variables in the leniency score equation, this means that none of the observable variables have strong predictive power for leniency. None of the 170 variables were selected for the leniency equation by the Lasso, which further confirms that the observed characteristics are uncorrelated with the instrument.

\section{Assumption 3: monotonicity}

The monotonicity assumption means that assessors who are stricter for one group of applicants are also stricter for all other subgroups. It implies that the relationship between assessor leniency and the probability of being rated eligible to move to a nursing home is

\footnotetext{
${ }^{23}$ A close alternative to this test is to split the population in quartiles using the leniency of the assessor, and to test for differences in other characteristics between these quartiles. The results from this test reconfirmed the results reported here (full results available upon request).
} 
positive for all observable subgroups (French and Song 2013; Dahl et al. 2014). If this assumption holds, the leniency measure coefficient will always be nonnegative in subgroupspecific first-stage regressions. We found that, for all 19 subgroups considered, the first-stage coefficients were positive and close to the estimate for the entire population (Table 2).

Furthermore, a survival analysis of the population that was eligible for nursing home care demonstrates that individuals who were assessed by a more lenient assessor move to a nursing home at a slower rate (results available upon request). This implies that individuals granted a NHA by a stricter assessor are on average less healthy than those granted it by a more lenient assessor. Thus, this finding confirms that the monotonicity assumption is not rejected (cf. Maestas et al. 2013).

\section{Results}

\section{A. Main analyses}

As expected, being granted eligibility for a NHA increases the probability of moving to a nursing home (Table 3). This effect varies over time for three reasons: i) because not all those eligible move to a nursing home; ii) because those who do move to a nursing home do not move there immediately; and, iii) because a large share of applicants initially turned down eventually become eligible for a NHA. The effect is 15.6 percentage points after three months. It peaks after six months when the impact is 18.4 percentage points, and decreases to 11.1 percentage points after two years.

Being eligible for a NHA has no significant impact on mortality. The estimates are not significant and closer to zero than the OLS estimates (see Table A5 in Appendix A). Nor does it affect morbidity, as measured by the Charlson index. Yet, being eligible for a NHA 
means that an applicant is 8.9 percentage points (28 percent) less likely to incur a hospital admission. ${ }^{24}$

Being eligible for a NHA has a large impact on healthcare spending. As a consequence of the higher share of patients that are admitted to a nursing home among the eligible, their spending on nursing home care is 7,991 Euro higher after a year (12,447 after two years), while their home-care expenditures are 6,405 Euro lower (11,137 after two years). Moreover, the eligible are estimated to spend 1,500 Euro less on medical care than the ineligible in the calendar year after the eligibility decision (Table 3). This drop fully offsets the increase in LTC spending, meaning that the total effect of becoming eligible for a NHA on healthcare spending is close to zero. This drop in medical care costs is not the result of differences in mortality between home care and nursing home care recipients, as the 2SLS shows no significant effect of a NHA on mortality. Hence, a NHA limits the need to seek medical help and thus medical care spending, either because the nursing home provides this care itself, because living in a nursing home improves the health of the residents, or because the nursing home staff are able to improve timeliness of medical care.

\section{B. Characteristics of compliers}

The 2SLS and the OLS results are not directly comparable because the 2SLS results apply to the compliers, while the OLS results apply to the full population. The size of the compliers group is equal to the first-stage coefficient multiplied by the difference between the eligibility rate of the least and most-lenient assessor (Maestas et al. 2013). This means that 46 percent of the population is at the margin. The group of "always takers” (i.e. those always considered eligible) is equal to the share considered eligible by the strictest assessor, while the group of

\footnotetext{
${ }^{24}$ Subsequent analyses on the number of days stayed at the hospital (conditional on one admission), the number of unscheduled admissions and on the probability of being admitted at least once for specific groups of conditions did not yield significant results (results available upon request).
} 
never takers is equal to the share considered ineligible by the most lenient assessor. In our case, a large share (54 percent) will always be considered eligible, while there are no never takers. The absence of never takers in the study population can be explained by our selection of individuals who apply for a NHA who are generally all in poor health.

The composition of the compliers group is different from the full study population. The relative likelihood estimates show that the compliers are substantially more likely to be aged 80-89 and over than the full study population (Table 2). They are also more likely to be in the lowest income quartile, to have submitted their application themselves and to have not been eligible for home care in the 30 days before the application. These groups that are overrepresented among the compliers might provide more room - or more reason - for discretionary decisions by assessors. The findings also suggest that the difference between the OLS estimates and the 2SLS is the result of differences between compliers and the full population as well as the impact that self-selection has on the OLS estimates (Dahl et al. 2015).

\section{Subgroup analyses}

Table 4 shows that assessor leniency has a larger impact on ENHA for some groups than for others: the effect of assessor leniency was largest for applicants in the 80-90 age group, applicants who file the application themselves, and applicants not eligible for home care at the time of the application. For these three subgroups, we re-estimate the 2SLS regressions for the probability of a NHA, mortality and LTC spending. For the first two subgroups, results are very similar to the overall result. However, applicants not eligible for home care at the time of application experience a drop of 8.4 percentage points in one-year mortality because of ENHA (Table 4). Because individuals in this group apply for a NHA, without previously using any form of home care, it seems likely that they have experienced a shock in 
their health or living conditions. We do, however, not find any consistent evidence for this based on their healthcare use prior to their application or changes in their marital status. Conversely, the mortality of the group that is eligible for home care when they apply is about 8.9 percentage points higher one year after they became eligible for a NHA. The effects of eligibility on a NHA and on LTC spending are similar for both subgroups and equal to those for the total population.

Effects of NHA eligibility might also differ across groups with different unobserved characteristics (e.g. unobserved health). Estimating the marginal treatment effects is one way to test for heterogeneous treatment effects over unobserved characteristics (Heckman et al., 2006). If we suppose there is only one unobservable factor (unobserved health) then differences in leniency (conditional on the observables) across assessors can be interpreted as differences in the threshold the assessors apply regarding this unobserved factor: lenient assessors apply a lower threshold with regard to unobserved health than strict assessors. The differences in leniency across assessors, which should be uncorrelated to unobserved health, allow us to estimate effects for different margins of eligibility by first estimating the propensity of eligibility based on leniency, and then estimating the outcome as a function of this propensity score ${ }^{25}$.

We estimate marginal treatment effects with NHA and mortality as outcomes. We do not find evidence of heterogeneity in the outcomes according to the propensity score ${ }^{26}$. These findings (available upon request) suggest that the effects of eligibility for a NHA do not differ across individuals with different severity of unobserved health problems. However, the effects can

\footnotetext{
${ }^{25}$ Specifically, we follow a similar approach to Maestas et al. (2013) and proceed in four steps. We first estimate an adjusted leniency measure correcting for all covariates used in the main analysis. Second, we estimate a probit model of eligibility on this indicator. The predictions from this model provide the propensity score (i.e. the predicted probability of being eligible). Third, we regress the outcomes on this score, using a local polynomial regression model. Fourth, numerically taking derivatives of this model gives the marginal treatment effects.

${ }^{26}$ The estimates depend very strongly on the functional form (order of the polynomial) that is chosen and even a second-order polynomial seems to suffer from overfitting. However, scatterplots of the average outcome by percentiles of the propensity score clearly show there is no heterogeneity in the effects.
} 
only be identified for compliers; always takers are likely to be in worse unobserved health than compliers. The results therefore cannot be generalized to the elderly population with very severe unobserved health problems. Furthermore, the idea of a single unobserved (health) factor may be an oversimplification of reality. When there is more than one factor that determines the eligibility decisions of the assessors (e.g. multiple health dimensions, such as morbidity, disability and frailty [Fried et al. 2004], or other factors such as living conditions), then the interpretation of the marginal treatment effects is less clear-cut since it becomes impossible to distinguish between the effects of the different factors.

\section{Robustness checks}

We performed three sets of robustness checks to verify whether the main results are sensitive to: i) the definition of the leniency measure; ii) decisions about the selection of control variables for applicant health status; and, iii) the linearity assumption for the instrument underlying the 2SLS regression models. The first set of tests revealed that the results are largely insensitive to decreasing (to 20 or 40 handled applications) or increasing (to 60, 80 or 100 applications) the threshold used to select assessors with sufficient numbers of observations to reliably calculate their leniency ${ }^{27}$. Further, using a version of the leniency measure that has not been corrected for characteristics of the application reconfirms the main analysis, except for the one-year mortality estimate, which is significant at the $\mathrm{p}<0.05$ level (Table 5). Finally, we tested if inexperienced assessors may receive an easier caseload (which would bias their leniency scores downward) by leaving out the 2.2 percent of applications handled by an assessor with fewer than 100 applications in the prior year. ${ }^{28}$ Leaving out these

\footnotetext{
${ }^{27}$ We document one exception: the one-year mortality effect of ENHA becomes positive and significant at the $\mathrm{p}$ $<0.05$ level when the threshold is set at 80 applications (but not at 100 applications).

${ }^{28}$ To measure the experience of the assessor, all types of application are taken into account, not just the type of applications used in the main analysis.
} 
applications does not alter the main result: there is a positive effect of being eligible for a NHA on the admission probability but not on mortality (Table 5).

Second, to gauge whether there is omitted variable bias related to the health of the applicants, as a first step we included information on spending on five categories of medical care hospital care, paramedical care, medical devices, medical transport and all other medical care - in the calendar year prior to the application. ${ }^{29}$ For all outcomes, results are identical to those in Section V.A.

To further verify whether we selected the correct covariates, we started with a much larger set of covariates including very detailed information on outpatient medicine use and diagnosis information from hospital admissions from the year prior to the application to the set of covariates used in the main analyses ${ }^{30}$ and let the Lasso developed by Tibshirani (1996) select relevant covariates in a data-driven way (Appendix C contains further details about the procedure). Specifically, we let the Lasso select the covariates that are associated with the endogenous variable, the instrument or the probability of a NHA (Belloni et al. 2014). This algorithm allowed us to consider a much larger set of covariates in a more structured way than we could do otherwise. The Lasso selected only a small share of the covariates included in the main analyses, and only four of the hospital diagnoses groups that were not included. The 2SLS results are not affected by the covariate selection.

Third, we verified whether the assumption that the effect of the instrument on eligibility for a NHA is linear by using dummy variables for ten leniency deciles as instruments rather than the continuous measure (cf. Dahl et al. 2015). The dummies revealed a linear effect and the estimates for the probability of a NHA and for mortality are very similar to the results with

\footnotetext{
${ }^{29}$ This information is not available for patients applying in 2009 and hence these observations $(\mathrm{n}=3$,696) were removed.

${ }^{30}$ Specifically, we added the categories of the International Shortlist for Hospital Morbidity Tabulation (ISHMT) and all ATC level-4 codes to the set of potential covariates.
} 
the continuous measure. Hence, the assumption of a linear instrument effect appears to have no effect on the estimates.

\section{Discussion and conclusion}

The share of elderly living in nursing homes has been declining steadily in recent decades. This is one of the most striking trends in LTC, with potentially far-reaching consequences for the health and well-being of the elderly as well as for (publicly financed) expenditures. But how large are these consequences really? This article sheds light on this question using a quasi-experimental approach.

In order to obtain a causal estimate of the effects of a NHA, we exploited two unique features of the Dutch institutional context. First, patients need to apply for eligibility for a NHA and these applications are reviewed by arbitrarily assigned assessors who differ in their leniency to grant eligibility. Second, virtually all LTC is publicly funded (CBS 2017), meaning that there are almost no options to bypass the public system - and hence the eligibility application procedure - and there are few other barriers to LTC use.

We find that for a substantial share of the elderly applying for a NHA, eligibility is affected by the leniency of the assessor handling their case. For this group, our two main findings are as follows. First, on average, eligibility for a NHA has no effect on mortality, nor does it affect health as measured by the Charlson index. Eligibility does, however, reduce the probability of having at least one hospital admission in the year following the eligibility decision.

The point estimate for the full population hides considerable heterogeneity of the effect of eligibility on mortality: ENHA leads to a sharp, but transient, increase in mortality for elderly who were using home care at the time of their application. Conversely, eligibility leads to a temporary decline in mortality for elderly who did not use home care at the time of their 
application. Discussions with experts and analysis of background characteristics of these subgroups did not provide insight into the underlying reason for this heterogeneity.

Second, ENHA has no impact on total healthcare spending. While nursing home care is expensive, the eligible would otherwise have absorbed an amount of home care that is almost equally expensive. Moreover, a NHA leads to cost savings through a substantial reduction in spending on medical care. While the estimate of the effect on LTC spending is in line with the findings presented in Kim and Lim (2015), they find a small positive effect of a NHA on medical care.

These findings imply that aging-in-place policies might not be the win-win they are often argued to be. While postponing a NHA does not seem to come at the cost of higher mortality risk, it does increase the risk of a hospital admission. Moreover, postponing NHAs does not lead to any cost savings. Such savings have often been cited as the main goal of these policies (OECD 2011). However, our analysis suggests that the health problems of the LTC applicants at the margin of eligibility are so severe that intensive care is needed to enable them to continue living at home. Our results indicate that provision of these intensive types of care at home might actually not be cost saving at all, possibly due to lack of (economies of) scale.

While our analysis sheds light on the causal effects of nursing home care on health and costs, we could not estimate all relevant societal costs and benefits of a NHA. Such a complete analysis is inhibited by a lack of information on a number of outcomes, the most important ones being the well-being of the patients and the health, well-being, and labor supply of the informal caregivers. It is an important finding that substitution to home care does not have major effects on health, but elderly do not only move to a nursing homes to prevent deterioration of their health. Rather, they might also move there to be able to cope with their health problems and limitations, and to lead a meaningful life despite these problems. 
Unfortunately, population-wide quality of life or happiness measures for people receiving home care or living in a nursing home are not available ${ }^{31}$. The same is true for data on informal care provision. A NHA is likely to affect the demand for informal care which, in turn, may have an impact on the health and wellbeing of the informal caregiver.

When generalizing the results to other institutional settings, two things are important. First, we have estimated a LATE for a specific subgroup. Our sample is restricted to applicants who themselves request eligibility for a NHA. It is likely that elderly with relatively mild health problems will (almost) never apply for nursing home care but rather for home care, and our sample thus excludes the applicants with the least severe health problems. Our estimates also do not pertain to applicants in such poor health that they are determined eligible even by the strictest assessors.

Second, the context of the Dutch LTC system should be taken into account. On the one hand, The Netherlands still has a relatively large proportion of its population aged over 65 years residing in nursing homes: 5.3 percent in 2014 compared to the OECD average of 3.8 percent (OECD 2017). It is therefore conceivable that relatively healthy patients are admitted to nursing homes, implying that the group of elderly for whom home care is a reasonable alternative is probably smaller in countries with a less comprehensive system. If we believe that home care is relatively expensive for elderly with more severe health problems, a costsaving effect of more home-care provision is even less likely for them. On the other hand, The Netherlands also has very extensive publically financed home-care provision. This means that, compared to other countries, individuals who are not eligible for a NHA still receive substantial home care, which may explain the similarity of health outcomes, but also the limited difference in costs.

\footnotetext{
${ }^{31}$ Kok et al. (2013) report that elderly in nursing homes are happier than elderly receiving care at home, but they rely on propensity score matching to identify effects.
} 
A final important element of the Dutch system is the assessment procedure: applicants who are not eligible for a NHA now, can reapply later and obtain quick access to a nursing home if their health problems worsen. In such a system, a strict initial assessment may be less consequential for health as it prevents unnecessary admissions for elderly who can indeed stay at home, while elderly for whom an admission is needed can still get access to a nursing home in time.

All in all, and perhaps somewhat surprising, we conclude that - at the margin, and taking into account the kind of outcomes that we can observe like mortality and costs - the current Dutch LTC system does not seem to suffer from any serious misallocation of resources. Had we found that the implicit admission eligibility thresholds used by the assessment procedure led to substantial additional costs or mortality risks at either side of the threshold, then it could have been appropriate to recommend a more or a less lenient procedure to rectify this situation. Based on our findings, however, the current system seems to get the balance between home care and nursing home care right, at least on average. 


\section{References}

Abbring J, Van den Berg G. 2005. Social experiments and instrumental variables with duration outcomes. Tinbergen Institute Discussion Paper 05-047/3. Amsterdam: Tinburgen Institute.

Algemene Rekenkamer. 2015. Regionale verschillen in de langdurige zorg. Mogelijke verklaringen voor zorggebruik van ouderen en chronisch zieken. The Hague: Algemene Rekenkamer.

Alders P, Costa-Font J, De Klerk M, Frank R. 2015. What is the impact of policy differences on nursing home utilization? The cases of Germany and the Netherlands. Health Policy 119: 814-820.

Angrist J, Pischke J. 2009. Mostly Harmless Econometrics. Princeton: Princeton University Press.

Autor D, Maestas N, Mullen K, Strand A. 2015. Does delay cause decay? The effect of administrative decision time on the labor force participation and earnings of disability applicants. National Bureau of Economic Research, Working Paper 20840. Cambridge Massachusetts: National Bureau of Economic Research.

Bakx P, Chernichovsky D, Paolucci F, Schokkaert E, Trottmann M, Wasem J, Schut F. 2015. Demand-side strategies to deal with moral hazard in public insurance for LTC. Journal of Health Services Research \& Policy 20, 3: 170-176.

Bakx P, Douven R, Schut FT. 2016a. Does independent needs assessment limit supply-side moral hazard in LTC? Centraal Planbureau/Sociaal en Cultureel Planbureau (CPB) Discussion paper 327. The Hague: CPB.

Bakx P, O’Donnell O, Van Doorslaer E. 2016b. Spending on health care in The Netherlands: not going so Dutch. Fiscal Studies 37 nos. 3-4: 593-625.

Belloni A, Chen D, Chernozhukov V, Hansen C. 2012. Sparse models and methods for optimal instruments with an application to eminent domain. Econometrica 80, no. 6: 2369-2429.

Belloni A, Chernozhukov V, Hansen C. 2014. High-dimensional methods and inference on structural and treatment effects. The Journal of Economic Perspectives 28 (2): 29-50.

Benjamini Y, Hochberg Y. 1995. Controlling the false discovery rate: a practical and powerful approach to multiple testing. Journal of the Royal Statistical Society, Series B 57(1): 289-300

Bishop, C. E. (1999). Where are the missing elders? The decline in nursing home use, 1985 and 1995. Health Affairs, 18 (4): 146-155.

Cellini S, Ferreira F, Rothstein J. 2010. The value of school facility investments: Evidence from a dynamic regression discontinuity design. Quarterly Journal of Economics 125: 215-261.

Chappell N, Dlitt B, Hollander M, Miller J, McWilliam C. 2004. Comparative costs of home care and residential care. The Gerontologist 44 (3): 389-400.

Centraal Bureau voor de Statistiek (CBS). 2016. Monitor Langdurige Zorg. Accessed April 28, 2016. mlzstatline.cbs.nl

Centraal Bureau voor de Statistiek (CBS). 2017. Ruim 700 euro eigen betalingen aan zorg in 2015. Accessed March 9, 2017. https://www.cbs.nl/nl-nl/nieuws/2017/07/ruim-700euro-eigen-betalingen-aan-zorg-in-2015

Centrum Indicatiestelling Zorg (CIZ). 2011. Kwartaalmonitor indicatiemelding 2011 vierde kwartaal. Accessed April 28, 2016. https://www.ciz.nl/voorprofessionals/Documents/Kwartaalmonitor_Indicatiemelding_2011_vierde_kwartaal.pd f

Centrum Indicatiestelling Zorg (CIZ). 2013. Indicatiewijzer 6.0. Accessed April 28, 2016 
https://www.ciz.nl/voor-professionals/Documents/Indicatiewijzer_60.pdf

Centrum Indicatiestelling Zorg (CIZ). 2014. Jaardocument 2013. Accessed April 28, 2016.

http://www.carta.nl/ciz-jaardocument2013/

Centraal Planbureau/Sociaal en Cultureel Planbureau (CPB). 2015. Keuzeruimte in de langdurige zorg. The Hague: CPB.

College Voor Zorgverzekeringen. 2013. Wachtlijstonderzoek AWBZ. Factoren die van invloed zijn op de betrouwbaarheid van wachtlijstinformatie. Diemen: CVZ.

Dahl G, Kostøl A, Mogstad M. 2014. Family Welfare Cultures. Quarterly Journal of Economics 129: 1711-1752

De Meijer C, Bakx P, Koopmanschap M, van Doorslaer E. 2015. Explaining declining rates of institutional LTC use in The Netherlands: a decomposition approach. Health Economics 24: S18-S31.

Doyle J. 2007. Child protection and child outcomes: measuring the effects of foster care. American Economic Review 97 (5): 1583-1610.

Eberwein C, Ham C, Lalonde R. 1997. "The impact of being offered and receiving classroom training on the employment histories of disadvantaged women: evidence from experimental data.” The Review of Economic Studies 64 (4): 655-682

French E, Song J. 2014. "The effect of disability insurance receipt on labor supply." American Economic Journal: Economic Policy 6: 291-337.

Fried L, Ferrucci L, Darer J, Williamson J, Anderson G. 2004. "Untangling the concepts of disability, frailty, and comorbidity: implications for improved targeting and care." Journal of Gerontolology, series A 59 (3):255-63.

Goffman E. 2009. Asylums. Essays on the social situation of mental patients and other inmates. Garden City: Anchor Books.

Guo J, Konetzka T, Manning W. 2015. "The causal effects of home care use on institutional long-term care utilization and expenditures.” Health Economics 24 (S1): 4-17

Heckman J, Urzua S, Vytlacil E. 2006. "Understanding instrumental variables in models with essential heterogeneity." The Review of Economics and Statistics 88 (3): 389-432.

Hussem A, Van Ewijk C, ter Rele H, Wong A. 2016. "The ability to pay for long-term care in the Netherlands: a lifecycle perspective.” De Economist 164: 209-234

Kim H, W Lim. 2015. "Long-term care insurance, informal care, and medical expenditures.” Journal of Public Economics 125: 128-142

Kok L, Berden C, Sadiraj K. 2015. "Costs and benefits of home care for the elderly versus residential care: a comparison using propensity scores." The European Journal of Health Economics 16 (2): 119-131.

Lindeboom M, van der Klaauw B, Vriend S. 2016. "Audit rates and compliance: a field experiment in care provision." Journal of Economic Behavior and Organization 131 (B): 160-173

Lipsky M. 2010. Street Level Bureaucracy: Dilemmas of the Individual in Public Services. $30^{\text {th }}$ Anniversary Edition. New York: The Russell Sage Foundation.

Maestas N, Mullen K, Strand A. 2013. "Does disability insurance receipt discourage work? Using examiner assignment to estimate causal effects of SSDI receipt." American Economic Review 103: 1797-1829

Marek K, Stetzer F, Adams S, Popejoy L, Rantz M, 2012. “Aging in place versus nursing home care: comparison of costs to Medicare and Medicaid." Research in Gerontological Nursing 5(2): 123-129

McKnight R. 2006. "Home care reimbursement, long-term care utilization, and health outcomes.” Journal of Public Economics 90 (1): 293-323. 
Nederlandse Zorgautoriteit (NZA). 2011. Zorgzwaartepakketten Sector V\&V. Accessed April 28 , 2016. https://www.nza.nl/1048076/1048155/CA_300_510_bijlage_1_sector_V_V.pdf

Organization for Economic Cooperation and Development (OECD). 2011. Help Wanted? Providing and Paying for LTC. OECD Health Policy Studies. OECD: Paris.

Organization for Economic Cooperation and Development (OECD). 2015. Health at a Glance 2015: OECD Indicators. Paris: OECD Publishing.

Organization for Economic Cooperation and Development (OECD). 2017. Accessed March 9, 2017. Data.oecd.org.

National Institute for Public Health and the Environment (RIVM). 2008. Locaties Centrum Indicatiestelling Zorg 2008. Accessed April 28, 2016. http://www.zorgatlas.nl/zorg/gehandicaptenzorg/locaties-centrum-indicatiestellingzorg-2008/

National Institute for Public Health and the Environment (RIVM). 2012. Locaties Centrum Indicatiestelling Zorg. Accessed April 2016 http://www.zorgatlas.nl/zorg/langdurige-zorg/locaties-centrum-indicatiestellingzorg/\#breadcrumb]

Sundararajan V, Henderson T, Perry C, Muggivan A, Quan H, Ghali W. 2004. "New ICD-10 version of the Charlson comorbidity index predicted in-hospital mortality." Journal of Clinical Epidemiology 57 (1): 1288-1294

Tibshirani R. 1996. "Regression shrinkage and selection via the Lasso." Journal of the Royal Statistical Society Series B (Methodological) 58 (1): 267-288.

Weissert W, Frederick L. 2013. "The woodwork effect: estimating it and controlling the damage.” Journal of Aging \& Social Policy 25(2): 107-133

Wet Toelating Zorginstellingen (WTZI). 2016. Bouwregime. Accessed April 28, 2016. https://www.wtzi.nl/veelgesteldevragen/bouwregime/default.aspx

Wooldridge J. 2010. Econometric analysis of cross section and panel data. $2^{\text {nd }}$ Edition. Cambridge, MA: MIT press 


\section{Figure 1: distribution of the leniency measure}

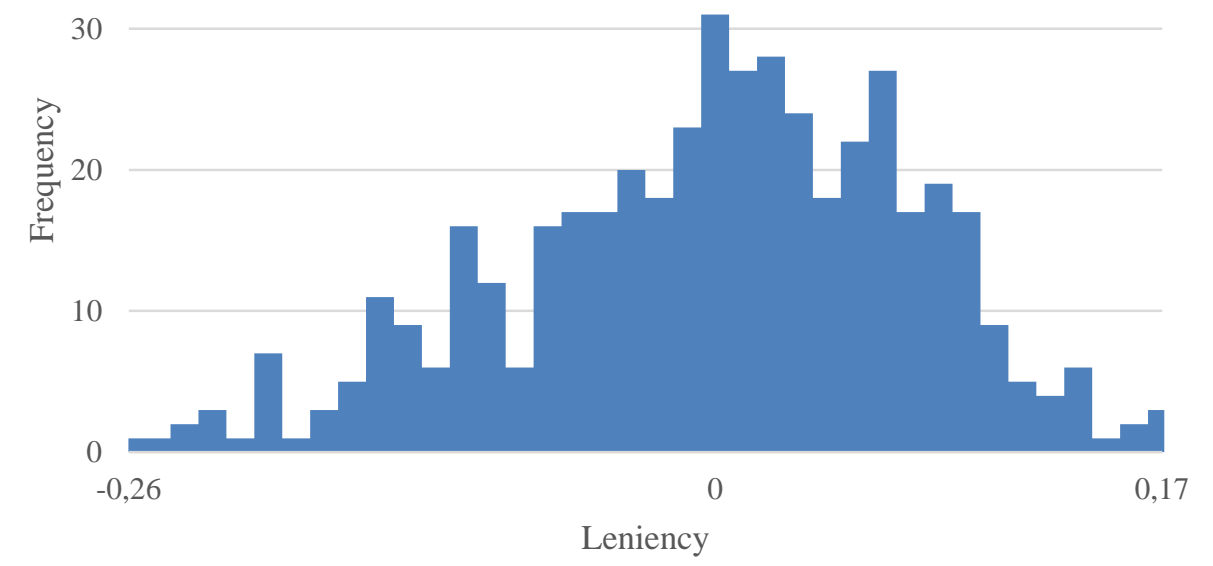

Note: the leniency measure is adjusted for the type of the application, the period and the region of residence of the applicant.

Table 1: Descriptive statistics: group means

\begin{tabular}{|c|c|c|c|c|}
\hline & \multirow{2}{*}{$\begin{array}{l}\text { Study } \\
\text { population } \\
\text { mean }\end{array}$} & \multicolumn{2}{|c|}{$\begin{array}{l}\text { Eligible for nursing home } \\
\text { admission (NHA) }\end{array}$} & \multirow{2}{*}{$\begin{array}{l}\text { Difference } \\
\text { between } \\
\text { subgroups }\end{array}$} \\
\hline & & No & Yes & \\
\hline \multicolumn{5}{|l|}{ Endogenous variable } \\
\hline ENHA & 0.835 & 0 & 1 & - \\
\hline \multicolumn{5}{|l|}{ Instrument } \\
\hline Leniency of the evaluator & 0 & -0.028 & 0.006 & $-0.034 * * *$ \\
\hline \multicolumn{5}{|l|}{ Outcomes } \\
\hline \multicolumn{5}{|l|}{ Mortality } \\
\hline 3-month & 0.042 & 0.020 & 0.047 & $-0.027 * * *$ \\
\hline 6-month & 0.085 & 0.046 & 0.092 & $-0.046^{* * *}$ \\
\hline 1-year & 0.161 & 0.104 & 0.172 & $-0.068 * * *$ \\
\hline 1.5-year & 0.232 & 0.160 & 0.247 & $-0.086 * * *$ \\
\hline 2-year & 0.304 & 0.217 & 0.321 & $-0.104 * * *$ \\
\hline \multicolumn{5}{|c|}{ Admitted to a nursing home within: } \\
\hline 3 months & 0.289 & 0.055 & 0.335 & $-0.279 * * *$ \\
\hline 6 months & 0.425 & 0.137 & 0.482 & $-0.344 * * *$ \\
\hline 1 year & 0.581 & 0.271 & 0.642 & $-0.371 * * *$ \\
\hline 1.5 years & 0.657 & 0.373 & 0.712 & $-0.339 * * *$ \\
\hline 2 years & 0.712 & 0.449 & 0.763 & $-0.314^{* * *}$ \\
\hline
\end{tabular}




\begin{tabular}{|c|c|c|c|c|}
\hline \multicolumn{5}{|l|}{ Long-term care expenditures } \\
\hline Nursing home care in the next year & 14142.83 & 4302.03 & 16087.21 & $-11785.18^{* * *}$ \\
\hline Nursing home care in the next 2 years & 34882.67 & 16254.36 & 38504.68 & $-22250.32^{* * *}$ \\
\hline Home care in the next year & 15107.34 & 14104.28 & 15305.52 & $-1201.24 * * *$ \\
\hline Home care in the next 2 years & 23023.45 & 26013.00 & 22442.18 & $3570.82^{* * *}$ \\
\hline \multicolumn{5}{|l|}{ Medical care expenditures } \\
\hline Next calendar year & 5951.92 & 7582.64 & 5620.00 & $1962.64 * * *$ \\
\hline Next 2 calendar years & 11225.97 & 13973.57 & 10640.69 & $3332.88^{* * *}$ \\
\hline \multicolumn{5}{|l|}{ Total healthcare expenditures } \\
\hline Next calendar year & 39786.97 & 31113.03 & 41552.46 & $-10439.43^{* * *}$ \\
\hline Next 2 calendar years & 84074.89 & 68206.05 & 87455.20 & $-19249.15^{* * *}$ \\
\hline \multicolumn{5}{|l|}{ Hospital care use } \\
\hline$\geq 1$ hospital admission in the next year & 0.32 & 0.358 & 0.312 & $0.046 * * *$ \\
\hline Charlson score in the next year & 0.258 & 0.266 & 0.257 & 0.009 \\
\hline \multicolumn{5}{|l|}{ Covariates $^{a}$} \\
\hline Eligible for home care in the past 30 days & 0.723 & 0.677 & 0.732 & $-0.054 * * *$ \\
\hline \multicolumn{5}{|l|}{ Applicant } \\
\hline Patient & 0.296 & 0.48 & 0.259 & $0.221 * * *$ \\
\hline GP & 0.027 & 0.028 & 0.026 & $0.002 * * *$ \\
\hline LTC provider & 0.294 & 0.176 & 0.317 & $-0.141^{* * *}$ \\
\hline Other $^{\mathrm{b}}$ & 0.383 & 0.316 & 0.398 & $-0.082^{* * *}$ \\
\hline \multicolumn{5}{|l|}{ Application type } \\
\hline Regular & 0.962 & 0.962 & 0.962 & 0.000 \\
\hline After emergency LTC & 0.013 & 0.011 & 0.013 & $-0.003 * *$ \\
\hline Other & 0.025 & 0.027 & 0.025 & $0.002 * *$ \\
\hline Random sample getting full assessment & 0.035 & 0.029 & 0.036 & $-0.007 * * *$ \\
\hline \multicolumn{5}{|l|}{ Sociodemographics } \\
\hline Age & 82.73 & 82.13 & 82.85 & $-0.72 * * *$ \\
\hline Female & 0.66 & 0.663 & 0.659 & 0.004 \\
\hline Household size & 1.47 & 1.47 & 1.46 & 0.01 \\
\hline Number of children & 2.42 & 2.44 & 2.42 & 0.02 \\
\hline Number of children in household & 0.044 & 0.046 & 0.043 & 0.003 \\
\hline Widowed in last year & 0.016 & 0.019 & 0.016 & $0.003^{* *}$ \\
\hline Widowed in last three months & 0.008 & 0.01 & 0.008 & 0.001 \\
\hline Standardized household income ${ }^{d}$ & 19954 & 19338 & 20075 & $-737 * * *$ \\
\hline Wealth & 189676 & 169172 & 193727 & $-24555^{* * *}$ \\
\hline Home owner & 0.335 & 0.314 & 0.339 & $-0.025 * * *$ \\
\hline Value of the home & 99983 & 92885 & 101385 & $-8500 * * *$ \\
\hline
\end{tabular}




\begin{tabular}{|c|c|c|c|c|}
\hline \multicolumn{5}{|l|}{ Past long-term care spending } \\
\hline Home care last year & 11298 & 6108 & 12323 & $-6215 * * *$ \\
\hline Home care past two years & 15606 & 9244 & 16864 & $-7620 * * *$ \\
\hline Nursing home care past two years & 138.49 & 141.46 & 137.90 & 3.563 \\
\hline \multicolumn{5}{|l|}{ Prescription drug use } \\
\hline ATC category B01 & 0.515 & 0.571 & 0.503 & $0.068^{* * *}$ \\
\hline ATC category J01 & 0.405 & 0.453 & 0.395 & $0.057 * * *$ \\
\hline ATC category A10 & 0.188 & 0.227 & 0.181 & $0.046^{* * *}$ \\
\hline Number of observations & 51047 & 8406 & 42641 & \\
\hline
\end{tabular}


Table 2: First-stage estimation results by subgroup

\begin{tabular}{|c|c|c|c|}
\hline & $\begin{array}{l}\text { Effect of leniency } \\
(\lambda)\end{array}$ & $\begin{array}{l}\text { Relative } \\
\text { likelihood }\end{array}$ & Observations \\
\hline Full population & $0.973(0.023)^{* * *}$ & 1 & 51047 \\
\hline Women & $1.012(0.028)^{* * *}$ & 1.04 & 33675 \\
\hline \multicolumn{4}{|c|}{ Healthcare spending last year } \\
\hline 1st quartile & $0.782(0.041)^{* * *}$ & 0.80 & 12414 \\
\hline 2nd quartile & $1.014(0.047)^{* * *}$ & 1.04 & 12452 \\
\hline - 3rd quartile & $1.058(0.048)^{* * *}$ & 1.09 & 12447 \\
\hline 4th quartile & $1.054(0.049)^{* * *}$ & 1.08 & 12446 \\
\hline \multicolumn{4}{|l|}{ Age } \\
\hline $65-69$ & $0.776(0.130)^{* * *}$ & 0.80 & 1746 \\
\hline $70-79$ & $0.920(0.043)^{* * *}$ & 0.95 & 13916 \\
\hline $80-89$ & $1.038(0.031)^{* * *}$ & 1.07 & 27748 \\
\hline 90 and over & $0.851(0.054)^{* * *}$ & 0.87 & 7637 \\
\hline \multicolumn{4}{|l|}{ Home care user } \\
\hline Yes & $0.901(0.026)^{* * *}$ & 0.93 & 14158 \\
\hline No & $1.140(0.047)^{* * *}$ & 1.17 & 36889 \\
\hline \multicolumn{4}{|c|}{ Prior nursing home admission } \\
\hline Yes & $0.968(0.023)^{* * *}$ & 0.99 & 2947 \\
\hline No & $1.080(0.092)^{* * *}$ & 1.11 & 48100 \\
\hline \multicolumn{4}{|l|}{ Applicant } \\
\hline Patient & $1.446(0.048)^{* * *}$ & 1.49 & 15097 \\
\hline LTC provider & $0.724(0.035)^{* * *}$ & 0.74 & 14989 \\
\hline Other & $0.774(0.038)^{* * *}$ & 0.80 & 20961 \\
\hline \multicolumn{4}{|c|}{ Standardized household income } \\
\hline 1st quartile & $1.040(0.049)^{* * *}$ & 1.07 & 12761 \\
\hline 2nd quartile & $0.959(0.049) * * *$ & 0.99 & 12761 \\
\hline 3rd quartile & $1.051(0.049)^{* * *}$ & 1.08 & 12763 \\
\hline 4th quartile & $0.839(0.048)^{* * *}$ & 0.86 & 12762 \\
\hline
\end{tabular}


Table 3: The impact of becoming eligible for a nursing home admission (NHA)

\begin{tabular}{|c|c|c|c|c|c|}
\hline \multirow[b]{3}{*}{ Effect of ENHA $(\gamma)$} & \multicolumn{5}{|c|}{ A NHA within: } \\
\hline & 3 months & 6 months & 1 year & 1.5 year & 2 year \\
\hline & $\begin{array}{l}0.156 \\
(0.028)^{* * *}\end{array}$ & $\begin{array}{l}0.205 \\
(0.031)^{* * *}\end{array}$ & $\begin{array}{l}0.184 \\
(0.031)^{* * *}\end{array}$ & $\begin{array}{l}0.137 \\
(0.032)^{* * *}\end{array}$ & $\begin{array}{l}0.111 \\
(0.031)^{* * *}\end{array}$ \\
\hline \multicolumn{6}{|l|}{ First stage } \\
\hline $\begin{array}{l}\text { Effect of leniency } \\
(\lambda)\end{array}$ & $\begin{array}{l}0.973 \\
(0.023) * * *\end{array}$ & $\begin{array}{l}0.973 \\
(0.023)^{* * *}\end{array}$ & $\begin{array}{l}0.973 \\
(0.023) * * *\end{array}$ & $\begin{array}{l}0.963 \\
(0.026) * * *\end{array}$ & $\begin{array}{l}0.963 \\
(0.026)^{* * *}\end{array}$ \\
\hline $\begin{array}{l}\text { F-statistic leniency } \\
\text { (p-value) }\end{array}$ & $\begin{array}{l}1599 \\
(0.000)^{* * *}\end{array}$ & $\begin{array}{l}1599 \\
(0.000)^{* * *}\end{array}$ & $\begin{array}{l}1599 \\
(0.000)^{* * *}\end{array}$ & $\begin{array}{l}1379 \\
(0.000)^{* * *}\end{array}$ & $\begin{array}{l}1379 \\
(0.000)^{* * *}\end{array}$ \\
\hline Partial $\mathrm{R}^{2}$ leniency & 0.035 & 0.035 & 0.035 & 0.035 & 0.035 \\
\hline $\begin{array}{l}\text { Number of } \\
\text { observations }\end{array}$ & 51047 & 51047 & 51047 & 44261 & 44261 \\
\hline
\end{tabular}

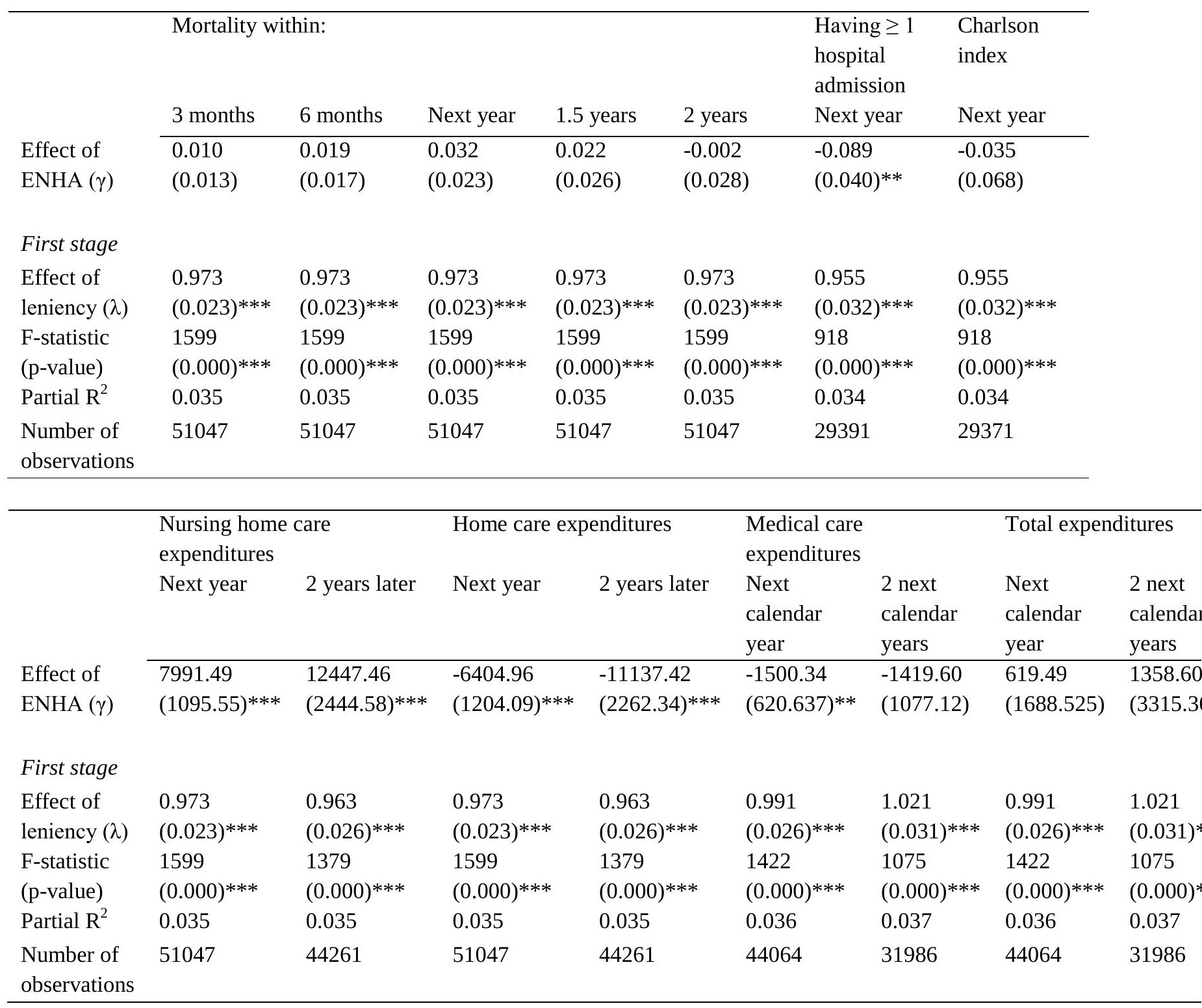


Table 4: Subgroup analyses

\begin{tabular}{|c|c|c|c|c|}
\hline & Home care user & $\begin{array}{l}\text { Not a home care } \\
\text { user }\end{array}$ & $\begin{array}{l}\text { Applicant is } \\
\text { patient }\end{array}$ & Age: $80-90$ \\
\hline \multicolumn{5}{|l|}{ Effect of ENHA on: } \\
\hline 1-year mortality & $0.089(0.030)^{* * *}$ & $-0.084(0.034)^{* *}$ & $0.006(0.025)$ & $0.026(0.028)$ \\
\hline 2-year mortality & $0.028(0.037)$ & $-0.060(0.043)$ & $-0.000(0.032)$ & $-0.012(0.035)$ \\
\hline 1-year nursing home admission & $0.184(0.038)^{* * *}$ & $0.156(0.051)^{* * *}$ & $\begin{array}{l}0.210 \\
(0.038) * * *\end{array}$ & $\begin{array}{l}0.150 \\
(0.039) * * *\end{array}$ \\
\hline 2-year nursing home admission & $0.113(0.039)^{* * *}$ & $0.081(0.051)$ & $\begin{array}{l}0.156 \\
(0.040)^{* * *}\end{array}$ & $0.088(0.039)^{* *}$ \\
\hline $\begin{array}{l}\text { 1-year nursing home care } \\
\text { spending }\end{array}$ & $\begin{array}{l}8633.287 \\
(1440.858)^{* * *}\end{array}$ & $\begin{array}{l}6295.128 \\
(1585.091)^{* * *}\end{array}$ & $\begin{array}{l}4014.789 \\
(1023.326)^{* * *}\end{array}$ & $\begin{array}{l}8037.695 \\
(1321.929)^{* * *}\end{array}$ \\
\hline $\begin{array}{l}\text { 2-year nursing home care } \\
\text { spending }\end{array}$ & $\begin{array}{l}12121.929 \\
(3263.397)^{* * *}\end{array}$ & $\begin{array}{l}11181.462 \\
(3474.033)^{* * *}\end{array}$ & $\begin{array}{l}8401.952 \\
(2496.820)^{* * *}\end{array}$ & $\begin{array}{l}11136.709 \\
(3006.009)^{* * *}\end{array}$ \\
\hline 1-year home care spending & $\begin{array}{l}-6983.781 \\
(1657.664)^{* * *}\end{array}$ & $\begin{array}{l}-4702.529 \\
(1370.344)^{* * *}\end{array}$ & $\begin{array}{l}-3657.784 \\
(1106.942)^{* * *}\end{array}$ & $\begin{array}{l}-7831.589 \\
(1492.073)^{* * *}\end{array}$ \\
\hline 2-year home care spending & $\begin{array}{l}-11375.838 \\
(3121.556)^{* * *}\end{array}$ & $\begin{array}{l}-9350.112 \\
(2729.587)^{* * *}\end{array}$ & $\begin{array}{l}-8050.732 \\
(2291.375)^{* * *}\end{array}$ & $\begin{array}{l}-10702.293 \\
(2800.084) * * *\end{array}$ \\
\hline \multicolumn{5}{|l|}{ First stage $^{a}$} \\
\hline Effect of leniency $(\lambda)$ & $0.901(0.028)^{* * *}$ & $1.140(0.050)^{* * *}$ & $\begin{array}{l}1.446 \\
(0.049) * * *\end{array}$ & $\begin{array}{l}1.038 \\
(0.034)^{* * *}\end{array}$ \\
\hline F-statistic leniency (p-value) & $1067(0.000)^{* * *}$ & $511(0.000)^{* * *}$ & $859(0.000)^{* * *}$ & $960(0.000)^{* * *}$ \\
\hline Partial R² leniency & 0.032 & 0.041 & 0.057 & 0.038 \\
\hline Number of observations & 36889 & 14158 & 15097 & 27748 \\
\hline
\end{tabular}

Table 5: Robustness checks

\begin{tabular}{|c|c|c|c|c|}
\hline & $\begin{array}{l}\text { Experienced } \\
\text { assessors only }\end{array}$ & $\begin{array}{l}\text { Excluding all } \\
\text { applications of } \\
\text { the same type } \\
\text { when calculating } \\
\text { leniency }\end{array}$ & $\begin{array}{l}\text { Using leniency } \\
\text { decile indicators } \\
\text { as instruments }\end{array}$ & $\begin{array}{l}\text { Leniency } \\
\text { measure } \\
\text { calculated using } \\
\text { last year's } \\
\text { observations } \\
\text { only }\end{array}$ \\
\hline \multicolumn{5}{|l|}{ Effect of ENHA on: } \\
\hline 1-year mortality & $0.034(0.023)$ & $0.046(0.039)$ & $0.035(0.023)$ & $-0.059(0.064)$ \\
\hline 2-year mortality & $0.002(0.028)$ & $-0.014(0.048)$ & $0.001(0.029)$ & $-0.052(0.076)$ \\
\hline 1-year nursing home admission & $0.195(0.031)^{* * *}$ & $0.079(0.052)$ & $0.181(0.031)^{* * *}$ & $0.088(0.079)$ \\
\hline 2-year nursing home admission & $0.120(0.031)^{* * *}$ & $-0.007(0.053)$ & $0.109(0.031)^{* * *}$ & $-0.029(0.087)$ \\
\hline $\begin{array}{l}\text { 1-year nursing home care } \\
\text { spending }\end{array}$ & $\begin{array}{l}7976.648 \\
(1100.007)^{* * *}\end{array}$ & $\begin{array}{l}6613.110 \\
(1914.440)^{* * *}\end{array}$ & $\begin{array}{l}8396.388 \\
(1114.071)^{* * *}\end{array}$ & $\begin{array}{l}9153.860 \\
(2974.500)^{* * *}\end{array}$ \\
\hline $\begin{array}{l}\text { 2-year nursing home care } \\
\text { spending }\end{array}$ & $\begin{array}{l}12245.619 \\
(2453.391)^{* * *}\end{array}$ & $\begin{array}{l}8090.022 \\
(4306.991)^{*}\end{array}$ & $\begin{array}{l}13632.275 \\
(2481.590)^{* * *}\end{array}$ & $\begin{array}{l}8284.951 \\
(7219.529)\end{array}$ \\
\hline 1-year home care spending & $\begin{array}{l}-6506.958 \\
(1207.847)^{* * *}\end{array}$ & $\begin{array}{l}-8609.861 \\
(2123.677)^{* * *}\end{array}$ & $\begin{array}{l}-6026.848 \\
(1218.730)^{* * *}\end{array}$ & $\begin{array}{l}-11074.410 \\
(3341.277)^{* * *}\end{array}$ \\
\hline 2-year home care spending & $\begin{array}{l}-11360.770 \\
(2267.963)^{* * *}\end{array}$ & $\begin{array}{l}-13242.207 \\
(4045.018)^{* * *}\end{array}$ & $\begin{array}{l}-11106.662 \\
(2304.496)^{* * *}\end{array}$ & $\begin{array}{l}-18770.467 \\
(6605.768)^{* * *}\end{array}$ \\
\hline
\end{tabular}




\begin{tabular}{|c|c|c|c|c|}
\hline \multicolumn{5}{|l|}{ First stage $e^{a}$} \\
\hline Effect of leniency $(\lambda)$ & $0.979(0.025)^{* * *}$ & $0.592(0.024)^{* * *} \quad \mathrm{~b}$ & b & 0.3 \\
\hline $\begin{array}{l}\text { F-statistic leniency } \\
\text { (p-value) }\end{array}$ & $1590(0.000)^{* * *}$ & $596(0.000)^{* * *}$ & \multicolumn{2}{|c|}{$193(0.000)^{* * *}$} \\
\hline Partial $\mathrm{R}^{2}$ leniency & 0.035 & 0.014 & 0.034 & 0.0 \\
\hline Number of observations & 49942 & 43113 & 51047 & \\
\hline & $\begin{array}{l}\text { Only observations } \\
\text { from } 2011\end{array}$ & $\begin{array}{l}\text { Controlling for } \\
\text { confounding through } \\
\text { additional health } \\
\text { information }\end{array}$ & \multicolumn{2}{|c|}{$\begin{array}{l}\text { Using the Lasso } \\
\text { to select } \\
\text { covariates }^{c}\end{array}$} \\
\hline \multicolumn{5}{|l|}{ Effect of ENHA on: } \\
\hline 1-year mortality & $0.021(0.047)$ & $0.036(0.023)$ & \multicolumn{2}{|l|}{$0.035(0.029)$} \\
\hline 2-year mortality & $-0.042(0.056)$ & $0.008(0.028)$ & \multicolumn{2}{|l|}{$-0.011(0.037)$} \\
\hline 1-year nursing home admission & $0.155(0.058)^{* * *}$ & $0.193(0.031)^{* * *}$ & \multicolumn{2}{|c|}{$0.182(0.041)^{* * *}$} \\
\hline 2-year nursing home admission & $0.053(0.054)$ & $0.117(0.031)^{* * *}$ & \multicolumn{2}{|c|}{$0.102(0.038)^{* * *}$} \\
\hline $\begin{array}{l}\text { 1-year nursing home care } \\
\text { spending }\end{array}$ & $\begin{array}{l}6036.218 \\
(2033.050)^{* * *}\end{array}$ & $\begin{array}{l}8173.871 \\
(1103.299)^{* * *}\end{array}$ & \multicolumn{2}{|c|}{$\begin{array}{l}8080.507 \\
(1392.954)^{* * *}\end{array}$} \\
\hline $\begin{array}{l}\text { 2-year nursing home care } \\
\text { spending }\end{array}$ & $\begin{array}{l}11070.306 \\
(4437.200)^{* *}\end{array}$ & $\begin{array}{l}12574.342 \\
(2462.825)^{* * *}\end{array}$ & \multicolumn{2}{|c|}{$\begin{array}{l}15625.291 \\
(3036.446)^{* * *}\end{array}$} \\
\hline 1-year home care spending & $\begin{array}{l}-8853.132 \\
(2404.436) * * *\end{array}$ & $\begin{array}{l}-6668.339 \\
(1215.251)^{* * *}\end{array}$ & \multicolumn{2}{|l|}{-4734.161} \\
\hline 2-year home care spending & $\begin{array}{l}-16020.591 \\
(4121.336)^{* * *}\end{array}$ & $\begin{array}{l}-11616.974 \\
(2277.829)^{* * *}\end{array}$ & \multicolumn{2}{|c|}{$\begin{array}{l}-11411.966 \\
(2910.635)^{* * *}\end{array}$} \\
\hline \multicolumn{5}{|l|}{ First stage $e^{a}$} \\
\hline Effect of leniency $(\lambda)$ & $0.852(0.039)^{* * *}$ & $0.977(0.025)^{* * *}$ & \multicolumn{2}{|c|}{$0.954(0.030)^{* * *}$} \\
\hline $\begin{array}{l}\text { F-statistic leniency } \\
\text { (p-value) }\end{array}$ & $480(0.000)^{* * *}$ & $1574(0.000)^{* * *}$ & \multicolumn{2}{|c|}{$903(0.000)^{* * *}$} \\
\hline Partial $\mathrm{R}^{2}$ leniency & 0.03 & 0.035 & \multicolumn{2}{|l|}{0.034} \\
\hline Number of observations & 18144 & 49759 & \multicolumn{2}{|l|}{30065} \\
\hline
\end{tabular}

Lower bound on the number of observations needed to the calculate leniency of an assessor 20 40 60 80 100

\section{Effect of ENHA}

on:

\begin{tabular}{|c|c|c|c|c|c|}
\hline 1-year mortality & $0.024(0.019)$ & $0.035(0.022)$ & $0.031(0.023)$ & $0.058(0.026)^{* *}$ & $0.046(0.030)$ \\
\hline 2-year mortality & $-0.011(0.024)$ & $-0.000(0.027)$ & $-0.007(0.029)$ & 0.017 (0.033) & $-0.009(0.038)$ \\
\hline $\begin{array}{l}\text { 1-year nursing } \\
\text { home admission }\end{array}$ & $\begin{array}{l}0.237 \\
(0.027)^{* * *}\end{array}$ & $\begin{array}{l}0.189 \\
(0.029) * * *\end{array}$ & $0.185(0.031)^{* * *}$ & $\begin{array}{l}0.156 \\
(0.035)^{* * *}\end{array}$ & $\begin{array}{l}0.159 \\
(0.041)^{* * *}\end{array}$ \\
\hline $\begin{array}{l}\text { 2-year nursing } \\
\text { home admission }\end{array}$ & $\begin{array}{l}0.140 \\
(0.027)^{* * *}\end{array}$ & $\begin{array}{l}0.118 \\
(0.030)^{* * *}\end{array}$ & $0.113(0.031)^{* * *}$ & $0.069(0.036)^{*}$ & $0.072(0.042)^{*}$ \\
\hline $\begin{array}{l}\text { 1-year nursing } \\
\text { home care } \\
\text { spending }\end{array}$ & $\begin{array}{l}7038.263 \\
(933.167)^{* * *}\end{array}$ & $\begin{array}{l}7634.662 \\
(1045.668)^{* * *}\end{array}$ & $\begin{array}{l}7714.693 \\
(1109.888)^{* * *}\end{array}$ & $\begin{array}{l}8206.570 \\
(1255.915)^{* * *}\end{array}$ & $\begin{array}{l}7730.504 \\
(1450.847)^{* * *}\end{array}$ \\
\hline $\begin{array}{l}\text { 2-year nursing } \\
\text { home care } \\
\text { spending }\end{array}$ & $\begin{array}{l}10562.006 \\
(2078.024)^{* * *}\end{array}$ & $\begin{array}{l}11481.562 \\
(2338.268)^{* * *}\end{array}$ & $\begin{array}{l}11987.496 \\
(2487.653)^{* * *}\end{array}$ & $\begin{array}{l}13044.128 \\
(2845.953)^{* * *}\end{array}$ & $\begin{array}{l}11924.927 \\
(3295.639)^{* * *}\end{array}$ \\
\hline
\end{tabular}




\begin{tabular}{|c|c|c|c|c|c|}
\hline $\begin{array}{l}\text { 1-year home care } \\
\text { spending }\end{array}$ & $\begin{array}{l}-4535.525 \\
(998.934)^{* * *}\end{array}$ & $\begin{array}{l}-5966.951 \\
(1138.956)^{* * *}\end{array}$ & $\begin{array}{l}-6764.837 \\
(1218.846)^{* * *}\end{array}$ & $\begin{array}{l}-6981.734 \\
(1391.035)^{* * *}\end{array}$ & $\begin{array}{l}-7588.123 \\
(1587.319)^{* * *}\end{array}$ \\
\hline $\begin{array}{l}\text { 2-year home care } \\
\text { spending }\end{array}$ & $\begin{array}{l}-8234.621 \\
(1882.341)^{* * *} \\
0.024(0.019)\end{array}$ & $\begin{array}{l}-10387.997 \\
(2140.710)^{* * *} \\
0.035(0.022)\end{array}$ & $\begin{array}{l}-11661.382 \\
(2297.886)^{* * *} \\
0.031(0.023)\end{array}$ & $\begin{array}{l}-11656.574 \\
(2654.395)^{* * *} \\
0.058(0.026)^{* *}\end{array}$ & $\begin{array}{l}-11422.365 \\
(3037.802)^{* * *} \\
0.046(0.030)\end{array}$ \\
\hline \multicolumn{6}{|l|}{ First stage $e^{a}$} \\
\hline $\begin{array}{l}\text { Effect of leniency } \\
(\lambda)\end{array}$ & $\begin{array}{l}0.955 \\
(0.021)^{* * *}\end{array}$ & $\begin{array}{l}0.963 \\
(0.023)^{* * *}\end{array}$ & $0.970(0.025)^{* * *}$ & $\begin{array}{l}0.971 \\
(0.027)^{* * *}\end{array}$ & $\begin{array}{l}0.976 \\
(0.031)^{* * *}\end{array}$ \\
\hline $\begin{array}{l}\text { F-statistic leniency } \\
\text { (p-value) }\end{array}$ & $2021(0.000)$ & $1735(0.000)$ & $1558(0.000)$ & $1248(0.000)$ & $967(0.000)$ \\
\hline Partial $\mathrm{R}^{2}$ leniency & 0.04 & 0.036 & 0.036 & 0.033 & 0.03 \\
\hline $\begin{array}{l}\text { Number of } \\
\text { observations }\end{array}$ & 56075 & 52786 & 48985 & 42789 & 35542 \\
\hline
\end{tabular}

${ }^{a}$ For population with at least one year of data available. ${ }^{b}$ Coefficients for nine decile dummies range from .047 $(.008)^{* * *}$ for the second decile to $.232(.007)^{* * *}$ for the tenth. ${ }^{c}$ Covariates selected by the Lasso algorithm are: five period dummy variables, two region dummies, sixteen age-gender dummy variables, an indicator for being from Netherlands Antillean descent, ATC codes A02, A16, B01, B03, C01, C03, G04, H02, L01, L02, M01, M04, N06, R03 and Y, ISHMT codes 202, 501, 1006, and 1302, whether application was filed by the patient herself, whether application was filed by a care provider, household size and whether the patient is eligible for home care at the date of application. The lambda statistic is 1789.965802 


\section{Appendix A: Additional results}

Figure A.1: the number of applications for a nursing home admission per assessor

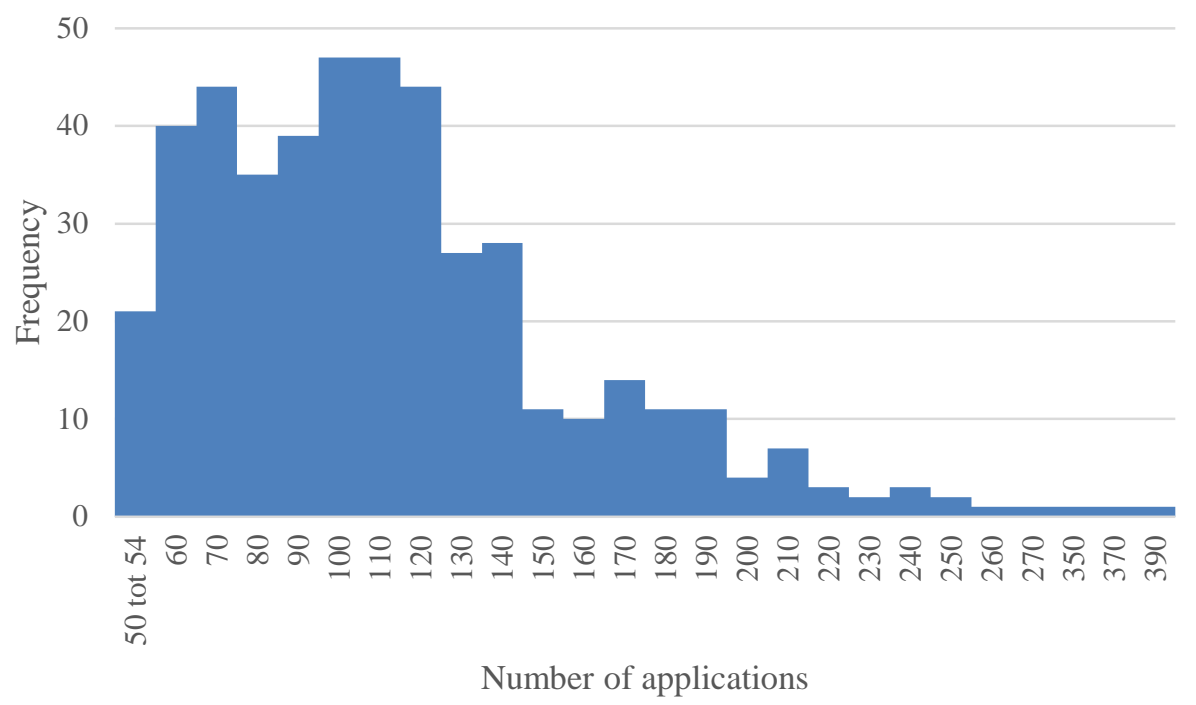

Note: assessors who handled fewer than 50 applications for a NHA are removed.

Figure A.2: distribution of the raw leniency measure 
Table A2: Additional descriptive statistics

\begin{tabular}{|c|c|c|c|c|}
\hline & Total sample & Not eligible & Eligible & Difference \\
\hline 2009, first half year & 0.034 & 0.052 & 0.030 & $0.022 * * *$ \\
\hline 2009, second half year & 0.049 & 0.069 & 0.045 & $0.023^{* * *}$ \\
\hline 2010, first half year & 0.065 & 0.082 & 0.062 & $0.021^{* * *}$ \\
\hline 2010, second half year & 0.120 & 0.119 & 0.121 & -0.001 \\
\hline 2011, first half year & 0.192 & 0.177 & 0.194 & $-0.017 * * *$ \\
\hline 2011, second half year & 0.164 & 0.135 & 0.170 & $-0.035 * * *$ \\
\hline 2012, first half year & 0.139 & 0.125 & 0.142 & $-0.018 * * *$ \\
\hline 2012, second half year & 0.104 & 0.096 & 0.106 & $-0.01 * * *$ \\
\hline 2013, first half year & 0.082 & 0.093 & 0.080 & $0.012 * * *$ \\
\hline 2013, second half year & 0.051 & 0.052 & 0.050 & 0.002 \\
\hline \multicolumn{5}{|l|}{ Region } \\
\hline 1 & 0.164 & 0.126 & 0.170 & $-0.044 * * *$ \\
\hline 2 & 0.036 & 0.060 & 0.031 & $0.028 * * *$ \\
\hline 3 & 0.074 & 0.109 & 0.068 & $0.041 * * *$ \\
\hline 4 & 0.109 & 0.101 & 0.111 & $-0.010 * * *$ \\
\hline 5 & 0.077 & 0.089 & 0.074 & $0.015^{* * *}$ \\
\hline 6 & 0.131 & 0.130 & 0.132 & -0.002 \\
\hline 7 & 0.119 & 0.109 & 0.121 & $-0.012 * * *$ \\
\hline 8 & 0.117 & 0.098 & 0.120 & $-0.022 * * *$ \\
\hline 9 & 0.125 & 0.133 & 0.124 & $0.009^{* *}$ \\
\hline 10 & 0.048 & 0.045 & 0.049 & $-0.004 *$ \\
\hline Not of foreign descent ${ }^{\mathrm{c}}$ & 0.893 & 0.878 & 0.896 & $-0.018 * * *$ \\
\hline Turkey & 0.004 & 0.010 & 0.003 & $0.008 * * *$ \\
\hline Morocco & 0.002 & 0.004 & 0.001 & $0.003^{* * *}$ \\
\hline Suriname & 0.008 & 0.011 & 0.007 & $0.004 * * *$ \\
\hline Netherlands Antilles & 0.002 & 0.001 & 0.002 & -0.001 \\
\hline Western & 0.087 & 0.089 & 0.087 & 0.003 \\
\hline Other non-Western & 0.004 & 0.007 & 0.004 & $0.002^{* * *}$ \\
\hline \multicolumn{5}{|l|}{ Used medicine from ATC category } \\
\hline A02 (Drugs for acid-related disorders) & 0.411 & 0.480 & 0.398 & $0.082 * * *$ \\
\hline A03 (Drugs for functional gastrointestinal disorders) & 0.063 & 0.072 & 0.062 & $0.010 * * *$ \\
\hline A04 (Anti-emetics and antinauseants) & 0.005 & 0.006 & 0.005 & 0.001 \\
\hline A06 (Drugs for constipation) & 0.270 & 0.303 & 0.263 & $0.040^{* * *}$ \\
\hline $\begin{array}{l}\text { A07 (Antidiarrheals, intestinal anti- } \\
\text { inflammatory/anti-infective agents) }\end{array}$ & 0.035 & 0.040 & 0.034 & $0.006^{* * *}$ \\
\hline A10 (Drugs used in diabetes) & 0.188 & 0.227 & 0.181 & $0.046^{* * *}$ \\
\hline A11 (Vitamins) & 0.077 & 0.083 & 0.076 & $0.007^{* *}$ \\
\hline A12 (Mineral supplements) & 0.189 & 0.204 & 0.186 & $0.018 * * *$ \\
\hline B01 (Antithrombotic agents) & 0.515 & 0.571 & 0.503 & $0.068 * * *$ \\
\hline B02 (Antihemorrhagics) & 0.011 & 0.011 & 0.011 & 0.000 \\
\hline B03 (Anti-anemic preparations) & 0.143 & 0.155 & 0.141 & $0.015^{* * *}$ \\
\hline B05 (Blood substitutes and perfusion solutions) & 0.014 & 0.015 & 0.014 & 0.001 \\
\hline
\end{tabular}




\begin{tabular}{|c|c|c|c|c|}
\hline C01 (Cardiac therapy) & 0.190 & 0.220 & 0.184 & $0.036^{* * *}$ \\
\hline C02 (Antihypertensives) & 0.011 & 0.015 & 0.011 & $0.004^{* * *}$ \\
\hline C03 (Diuretics) & 0.390 & 0.451 & 0.378 & $0.073^{* * *}$ \\
\hline C05 (Vasoprotectives) & 0.017 & 0.021 & 0.016 & $0.004 * * *$ \\
\hline C07 (Beta Blocking Agents) & 0.362 & 0.414 & 0.352 & $0.062 * * *$ \\
\hline C08 (Calcium channel blockers) & 0.177 & 0.209 & 0.170 & $0.038 * * *$ \\
\hline $\begin{array}{l}\text { C09 (Agents acting on the renin-angiotensin } \\
\text { system) }\end{array}$ & 0.384 & 0.452 & 0.371 & $0.081^{* * *}$ \\
\hline C10 (Lipid modifying agents) & 0.313 & 0.366 & 0.303 & $0.064^{* * *}$ \\
\hline D01 (Antifungals for dermatological use) & 0.053 & 0.060 & 0.052 & $0.008^{* * *}$ \\
\hline D02 (Emollients and protectives) & 0.167 & 0.185 & 0.163 & $0.022 * * *$ \\
\hline D05 (Antipsoriatics) & 0.007 & 0.008 & 0.006 & $0.002 *$ \\
\hline $\begin{array}{l}\text { D06 (Antibiotics and chemotherapeutics for } \\
\text { dermatological use) }\end{array}$ & 0.072 & 0.081 & 0.070 & $0.011^{* * *}$ \\
\hline D07 (Corticosteroids, dermatological preparations) & 0.177 & 0.215 & 0.170 & $0.046 * * *$ \\
\hline D11 (Other dermatological preparations) & 0.010 & 0.012 & 0.010 & $0.002^{* *}$ \\
\hline G01 (Gynecological anti-infectives and antiseptics) & 0.008 & 0.010 & 0.008 & $0.002^{* *}$ \\
\hline $\begin{array}{l}\text { G03 (Sex hormones and modulators of the genital } \\
\text { system) }\end{array}$ & 0.019 & 0.021 & 0.019 & 0.002 \\
\hline G04 (Urologicals) & 0.108 & 0.122 & 0.105 & $0.017 * * *$ \\
\hline H02 (Corticosteroids for systemic use) & 0.140 & 0.184 & 0.131 & $0.053^{* * *}$ \\
\hline H03 (Thyroid therapy) & 0.071 & 0.080 & 0.070 & $0.010^{* * *}$ \\
\hline H04 (Pancreatic hormones) & 0.005 & 0.005 & 0.005 & 0.000 \\
\hline J01 (Antibacterials for systemic use) & 0.405 & 0.453 & 0.395 & $0.057 * * *$ \\
\hline J02 (Antimycotics for systemic use) & 0.009 & 0.011 & 0.008 & $0.003^{* *}$ \\
\hline J05 (Antivirals for systemic use) & 0.008 & 0.010 & 0.007 & $0.003 * * *$ \\
\hline J07 (Vaccines) & 0.008 & 0.007 & 0.008 & -0.001 \\
\hline L01 (Antineoplastic agents) & 0.012 & 0.017 & 0.011 & $0.006 * * *$ \\
\hline L02 (Endocrine therapy) & 0.026 & 0.028 & 0.025 & 0.002 \\
\hline L04 (Immunosuppressants) & 0.010 & 0.014 & 0.009 & $0.006^{* * *}$ \\
\hline $\begin{array}{l}\text { M01 (Anti-inflammatory and antirheumatic } \\
\text { products) }\end{array}$ & 0.126 & 0.159 & 0.120 & $0.039 * * *$ \\
\hline M04 (Anti-gout preparations) & 0.036 & 0.044 & 0.035 & $0.010^{* * *}$ \\
\hline M05 (Drugs for treatment of bone diseases) & 0.097 & 0.116 & 0.094 & $0.022 * * *$ \\
\hline N01 (Anesthetics) & 0.019 & 0.024 & 0.018 & $0.005^{* * *}$ \\
\hline N02 (Analgesics) & 0.245 & 0.299 & 0.234 & $0.065^{* * *}$ \\
\hline N03 (Anti-epileptics) & 0.047 & 0.056 & 0.045 & $0.011^{* * *}$ \\
\hline N04 (Anti-pParkinson drugs) & 0.029 & 0.033 & 0.028 & $0.005^{* * *}$ \\
\hline N05 (Psycholeptics) & 0.216 & 0.182 & 0.223 & $-0.041 * * *$ \\
\hline N06 (Psychoanaleptics) & 0.249 & 0.220 & 0.254 & $-0.034 * * *$ \\
\hline N07 (Other nervous system drugs) & 0.038 & 0.049 & 0.036 & $0.013^{* * *}$ \\
\hline P01 (Antiprotozoals) & 0.007 & 0.009 & 0.006 & $0.003^{* * *}$ \\
\hline R01 (Nasal preparations) & 0.040 & 0.051 & 0.038 & $0.014^{* * *}$ \\
\hline R03 (Drugs for obstructive airway diseases) & 0.177 & 0.226 & 0.167 & $0.059 * * *$ \\
\hline R05 (Cough and cold preparations) & 0.037 & 0.047 & 0.035 & $0.012 * * *$ \\
\hline R06 (Antihistamines for systemic use) & 0.051 & 0.063 & 0.048 & $0.015^{* * *}$ \\
\hline S01 (Ophthalmologicals) & 0.230 & 0.270 & 0.222 & $0.048 * * *$ \\
\hline S02 (Otologicals) & 0.026 & 0.033 & 0.025 & $0.008 * * *$ \\
\hline
\end{tabular}




\begin{tabular}{lllll}
\hline V03 (All other therapeutic products) & 0.007 & 0.007 & 0.007 & 0.000 \\
Y (ATC code not filled in) & 0.089 & 0.093 & 0.088 & 0.005 \\
\hline
\end{tabular}

Table A3: First-stage estimation results

\begin{tabular}{|c|c|c|c|c|c|c|}
\hline & \multicolumn{6}{|c|}{ Nursing home admission advised } \\
\hline & (1) & (2) & (3) & (4) & (5) & (6) \\
\hline Effect of leniency $(\lambda)$ & $\begin{array}{l}0.988 \\
(0.024)^{* * *}\end{array}$ & $\begin{array}{l}0.989 \\
(0.023)^{* * *}\end{array}$ & $\begin{array}{l}0.988 \\
(0.023) * * *\end{array}$ & $\begin{array}{l}0.988 \\
(0.023) * * *\end{array}$ & $\begin{array}{l}0.989 \\
(0.023) * * *\end{array}$ & $\begin{array}{l}0.973 \\
(0.023)^{* * *}\end{array}$ \\
\hline Controlling for: & & & & & & \\
\hline Period & & $\mathrm{X}$ & $\mathrm{X}$ & $\mathrm{X}$ & $\mathrm{X}$ & $\mathrm{X}$ \\
\hline Region & & & $\mathrm{X}$ & $\mathrm{X}$ & $\mathrm{X}$ & $\mathrm{X}$ \\
\hline Type of application & & & & $\mathrm{X}$ & $\mathrm{X}$ & $\mathrm{X}$ \\
\hline $\begin{array}{l}\text { Demographics and household } \\
\text { characteristics }\end{array}$ & & & & & $\mathrm{X}$ & $\mathrm{X}$ \\
\hline Healthcare use & & & & & & $\mathrm{X}$ \\
\hline Number of observations & 51047 & 51047 & 51047 & 51047 & 51047 & 51047 \\
\hline Adjusted $\mathrm{R}^{2}$ & 0.033 & 0.04 & 0.049 & 0.082 & 0.09 & 0.106 \\
\hline $\begin{array}{l}\text { Number of independent } \\
\text { variables }\end{array}$ & 1 & 10 & 19 & 26 & 111 & 170 \\
\hline
\end{tabular}


Table A4: Regression of leniency on all covariates

\begin{tabular}{|c|c|}
\hline & Coefficient \\
\hline 2009, second half year & 0.000 \\
\hline 2010, first half year & 0.000 \\
\hline 2010, second half year & -0.001 \\
\hline 2011, first half year & -0.001 \\
\hline 2011, second half year & -0.001 \\
\hline 2012, first half year & -0.001 \\
\hline 2012, second half year & -0.001 \\
\hline 2013, first half year & -0.001 \\
\hline 2013, second half year & -0.001 \\
\hline Region 2 & -0.001 \\
\hline Region 3 & -0.001 \\
\hline Region 4 & 0.000 \\
\hline Region 5 & -0.001 \\
\hline Region 6 & 0.000 \\
\hline Region 7 & 0.000 \\
\hline Region 8 & 0.000 \\
\hline Region 9 & 0.000 \\
\hline Region 10 & 0.000 \\
\hline Eligible for home care in the past 30 days & 0.000 \\
\hline Application by patient & 0.001 \\
\hline GP applied on behalf of patient & 0.000 \\
\hline LTC provider applied on behalf of patient & 0.000 \\
\hline Regular application & 0.000 \\
\hline Application after emergency LTC & 0.001 \\
\hline Random sample getting full assessment & 0.002 \\
\hline Foreign descent: Turkey & -0.006 \\
\hline Foreign descent: Morocco & 0.012 \\
\hline Foreign descent: Suriname & -0.001 \\
\hline Foreign descent: Netherlands Antilles & 0.011 \\
\hline Foreign descent: Western & -0.001 \\
\hline Foreign descent: Other non-Western & 0.000 \\
\hline Household size & 0.001 \\
\hline Number of children & 0.000 \\
\hline Number of children in household & 0.001 \\
\hline Widowed in last year & -0.009 \\
\hline Widowed in last three months & 0.013 \\
\hline Standardized household income $\mathrm{e}^{\mathrm{e}}$ & 0.000 \\
\hline Wealth & 0.000 \\
\hline Homeowner & 0.002 \\
\hline Value of the home ${ }^{\mathrm{d}}$ & 0.000 \\
\hline A02 (Drugs for acid-related disorders) & 0.000 \\
\hline $\begin{array}{l}\text { A03 (Drugs for functional gastrointestinal } \\
\text { disorders) }\end{array}$ & 0.001 \\
\hline A04 & -0.004 \\
\hline A06 (Drugs for constipation) & -0.002 \\
\hline
\end{tabular}




\begin{tabular}{ll}
\hline A07 (Antidiarrheals, intestinal anti- & -0.002 \\
inflammatory/anti-infective agents) & -0.001 \\
A10 (Drugs used in diabetes) & 0.002 \\
A11 (Vitamins) & -0.001 \\
A12 (Mineral supplements) & -0.001 \\
B01 (Antithrombotic agents) & 0.004 \\
B02 (Antihemorrhagics) & 0.000 \\
B03 (Anti-anemic preparations) & 0.004 \\
B05 (Blood substitutes and perfusion & \\
solutions) & 0.002 \\
C01 (Cardiac therapy) & 0.004 \\
C02 (Antihypertensives) & 0.000 \\
C03 (Diuretics & -0.001 \\
C05 (Vasoprotectives & 0.000 \\
C07 (Beta blocking agents & -0.001 \\
C08 (Calcium channel blockers & 0.000 \\
C09 (Agents acting on the renin-angiotensin & \\
system & 0.000 \\
C10 (Lipid modifying agents & -0.002 \\
D01 (Antifungals for dermatological use & 0.000 \\
D02 (Emollients and protectives & -0.005 \\
D05 (Antipsoriatics & -0.001 \\
D06 (Antibiotics and chemotherapeutics for & 0.000 \\
dermatological use & -0.001 \\
D07 (Corticosteroids, dermatological & -0.001 \\
preparations & -0.001 \\
D11 (Other dermatological preparations & 0.001 \\
G01 (Gynecological anti-infectives and & 0.000 \\
antiseptics & \\
G03 (Sex hormones and modulators of the & -0.002 \\
genital system & \\
G04 (Urologicals & 0.000 \\
H02 (Corticosteroids for systemic use) & 0.001 \\
H03 (Thyroid therapy) & -0.001 \\
H04 (Pancreatic hormones) & 0.002 \\
J01 (Antibacterials for systemic use) & -0.001 \\
J02 (Antimycotics for systemic use) & 0.004 \\
J05 (Antivirals for systemic use) & 0.003 \\
J07 (Vaccines) & -0.004 \\
L01 (Antineoplastic agents) & -0.001 \\
L02 (Endocrine therapy) & -0.002 \\
L04 (Immunosuppressants) & 0.003 \\
M01 (Anti-inflammatory and anti-rheumatic & -0.001 \\
products) & \\
M04 (Anti-gout preparations) & \\
M05 (Drugs for treatment of bone diseases) & -000 \\
N01 (Anesthetics) & \\
N02 (Analgesics) & \\
\hline & \\
\hline
\end{tabular}




\begin{tabular}{ll}
\hline N05 (Psycholeptics) & 0.001 \\
N06 (Psychoanaleptics) & 0.000 \\
N07 (Other nervous system drugs) & 0.002 \\
P01 (Antiprotozoals) & -0.001 \\
R01 (Nasal preparations) & 0.000 \\
R03 (Drugs for obstructive airway diseases) & 0.000 \\
R05 (Cough and cold preparations) & 0.001 \\
R06 (Antihistamines for systemic use) & -0.002 \\
S01 (Ophthalmologicals) & 0.000 \\
S02 (Otologicals) & 0.003 \\
V03 (All other therapeutic products) & 0.001 \\
Y (ATC code not filled in) & -0.003 \\
Spending on home care last year & 0.000 \\
Spending on home care two years ago & 0.000 \\
Spending on nursing home care two years ago & 0.000 \\
& \\
Number of observations & 51047 \\
\hline
\end{tabular}

Note: ${ }^{* * *} \mathrm{p}<0.001,{ }^{* *} \mathrm{p}<0.01,{ }^{*} \mathrm{p}<0.05$. $\mathrm{p}$-values are adjusted for multiple testing. 
Table A5 OLS estimates of the association between eligibility for a nursing home admission (ENHA) and the outcome measures

\begin{tabular}{llllll}
\hline \multirow{5}{*}{ Effect of ENHA $(\gamma)$} & A NHA within: & & & \\
& 3 months & 6 months & 1 year & 1.5 year & 2 year \\
\cline { 2 - 6 } Number of observations & 0.257 & 0.304 & 0.321 & 0.290 & 0.269 \\
& $(0.004)^{* * *}$ & $(0.005)^{* * *}$ & $(0.006)^{* * * *}$ & $(0.006)^{* * *}$ & $(0.006)^{* * *}$ \\
\hline
\end{tabular}

\begin{tabular}{|c|c|c|c|c|c|c|}
\hline & $\begin{array}{l}\text { Mortality: } \\
\text { 3-months }\end{array}$ & 6-month & 1-year & 1.5-year & 2-year & $\begin{array}{l}\text { Having } \geq 1 \\
\text { hospital admission } \\
\text { Next year }\end{array}$ \\
\hline Effect of ENHA $(\gamma)$ & $\begin{array}{l}0.022 \\
(0.002)^{* * *}\end{array}$ & $\begin{array}{l}0.035 \\
(0.003) * * *\end{array}$ & $\begin{array}{l}0.046 \\
(0.004)^{* * *}\end{array}$ & $\begin{array}{l}0.055 \\
(0.004)^{* * *}\end{array}$ & $\begin{array}{l}0.065 \\
(0.005) * * *\end{array}$ & $-0.022(0.008) * * *$ \\
\hline Number of observations & 51047 & 51047 & 51047 & 51047 & 51047 & 29391 \\
\hline
\end{tabular}

\begin{tabular}{|c|c|c|c|c|c|c|}
\hline & \multicolumn{2}{|c|}{ Medical care expenditures } & \multicolumn{2}{|c|}{$\begin{array}{l}\text { Nursing home care } \\
\text { expenditures }\end{array}$} & \multicolumn{2}{|c|}{ Home-care expenditures } \\
\hline & $\begin{array}{l}\text { Next } \\
\text { calendar year }\end{array}$ & $\begin{array}{l}\text { Next } 2 \\
\text { calendar } \\
\text { years }\end{array}$ & Next year & Next 2 years & Next year & Next 2 years \\
\hline Effect of & -866.1 & 5577.2 & 8861.3 & 15888.1 & -3117.3 & -7756.8 \\
\hline ENHA $(\gamma)$ & $(132.1)^{* * *}$ & $(322.4)^{* * *}$ & $(151.2)^{* * *}$ & $(380.8)^{* * *}$ & $(200.4)^{* * *}$ & $(416.2)^{* * *}$ \\
\hline $\begin{array}{l}\text { Number of } \\
\text { observations }\end{array}$ & 44064 & 44064 & 51047 & 44261 & 51047 & 44261 \\
\hline
\end{tabular}




\section{Appendix B: The assessment procedure}

\section{The application}

Individuals who may need LTC - or a healthcare provider or family member on their behalf apply for an assessment by filling out a printed or online form and sending it to the LTC needs assessment agency (Centrum Indicatiestelling Zorg - CIZ) in their region ${ }^{32}$. This form contains information on: i) the patient's health problems; ii) the patient's functional limitations; iii) the care that the patients would like to receive; and, iv) some of the patient's background characteristics, including marital status and household composition. Subsequently, the application is reviewed by a screener, who determines if the application is valid and, if so, whether it may be approved by a back office employee ${ }^{33}$ or if it should be reviewed by an assessor. In the latter case, the screener also determines the review procedure to be followed: the abridged procedure (the majority - desk research and phone interviews), the standard procedure (face-to-face interview, if needed with a translator - always required in case of a forced admission (wet Bijzondere Opname Psychiatrisch Ziekenhuis) ${ }^{34}$ ) or the expanded procedure (face-to-face interview and review by a multidisciplinary team, which includes medical staff).

\section{Applications are assigned randomly to assessors}

The planner assigns the applications to assessors. An assessor evaluates roughly three standard-procedure applications or seven abridged-procedure applications per day and the vast majority of the assessors do both types of assessments. Assessors handle one of three types of applications - for elderly care, care for the disabled or long-term mental health care - but there is no further specialization. When assigning cases to assessors, the planner does not take information about the patient's health or care needs into account but rather the priority status of the application ${ }^{35}$ and the workload of the assessors.

There are a few exceptions to the random assignment of assessors. First, novice assessors get a reduced load of about five applications per day and may start by assessing relatively straightforward applications, e.g. applications of individuals with only a few limitations and no other complicating factors. Second, some characteristics of the assessors, which are most likely unrelated to patient's health or care needs, may play a role in the assignment of cases. For instance, when planning home visits, which are often part of the standard-procedure assessments, the travel time of assessors is taken into account and hence assessors are more likely to assess individuals who live close to their home town. ${ }^{36}$ Third, assessors fluent in a

\footnotetext{
${ }^{32}$ We use data from 2009 through 2013. The number of regions decreased from 36 in 2008 to 10 in 2012 (RIVM 2008, 2012).

${ }^{33}$ Back-office employees handle delegated reassessments (Herindicatie via taakmandaat - HIT) ${ }^{33}$, applications for types of care for which a standard procedure is available (Standaard Indicatieprotocol - SIP) and applications of elderly of 80 years and older (Indicatiemeldingen - since 2012)). These types of applications are often directly approved. However, a small number of the applications are checked by an assessor (Lindeboom et al. 2016). HITs are checked before the decision is made; SIPs are checked afterwards.

${ }^{34}$ Applications for which the provider indicated that there may be a need for a forced admission are not in the data.

${ }^{35}$ All applications must be handled within six weeks. However, some applications need to be handled within 24 or 48 hours.

${ }^{36}$ Only 14 percent of the assessment procedures in our study population included a home visit is.
} 
foreign language may be assigned more applicants who are fluent in that language but not in Dutch $^{37}$.

Assessors handle applications on their own, but may discuss difficult cases with other possibly more experienced - assessors. This implies that these other assessors may have an influence on the decision. Finally, screeners may handle the simplest cases themselves. The data show that it is unlikely that this applied to any of the applications in the study population.

\section{The assessment}

At the start of the assessment, the assessor has access to: i) information that is filled out on the application form; ii) information about prior LTC use; and, iii) the information collected when previous applications were assessed ${ }^{38}$. He/she decides which information needs to be verified or updated and which information is missing. To verify what is known or to obtain new information, the assessor may contact the patient, household and/or family members, the health insurer and healthcare providers (e.g. the GP or a LTC provider), who provide much of the information that the assessor uses and are often involved in filling out the application. Most of the information is gathered or verified by making semi-structured phone calls. The time it takes to complete an assessment depends on how much information needs to be verified or updated. If most of the information is already available from previous applications, the assessor often only needs to check for any changes in the patient's situation.

According to the assessment framework, the assessor takes into account the health, healthrelated limitations, living conditions, social environment, psychiatric and social functioning of the applicant and any other professional services and informal care the patient is receiving. However, the assessor has the freedom to determine which of these aspects are relevant and therefore determines which information is verified or collected. ${ }^{39,40}$ A random 5 percent sample of the applications ${ }^{41}$ gets a full review.

\section{The eligibility decision and follow-up}

The assessor decides about the types and amounts of LTC for which the applicant is eligible . For some situations that can easily be defined, as there are guidelines to recommend a certain level or type of care as a function of needs. Applications for which it is not clear a priori whether home care or institutional is the most appropriate are considered to be among the most difficult.

When an applicant is considered eligible for institutional care, the assessor is supported by an automatically generated recommendation when deciding on the type and level of institutional care. This recommendation is based on the information on the functional limitations registered. The assessors have the discretionary power to deviate from the amount of care

\footnotetext{
${ }^{37}$ Applicants who were not fluent in Dutch were often invited for consultation at times when an interpreter was available.

${ }^{38}$ Reassessments are not done by the same assessor.

39 Any preferences indicated on the application form do not play a role, according to the documentation about the assessment procedure (CIZ 2013). According to the assessor we interviewed, these preferences only incidentally play a role when making the eligibility decision.

${ }^{40}$ Availability of sufficient capacity to deliver the care that the applicant is eligible for is not taken into account by the assessor; assessors have no information on the availability of LTC supply.

${ }^{41}$ With the exception of HITs and SIPs.
} 
suggested in the guidelines and from the recommendations made by the algorithm. They do not need to motivate their decisions, though they may explain their decisions to the applicants and their families to improve their understanding of the process and the outcome.

A new eligibility decision fully replaces the previous one. If the applicant does not agree with the decision, he/she may appeal and the decision is reconsidered. ${ }^{42}$ The initial decision is usually only reversed because new or additional information regarding the patient's situation becomes available.

${ }^{42}$ The applicant appeals in less than 1percent of cases and. 25percent of these appeals are approved (CIZ 2014). 


\section{Appendix C: The Lasso procedure}

As a robustness check, we repeated the analysis with a much larger set of covariates including very detailed information on outpatient medicine use and diagnosis information from hospital admissions from the year leading up to the assessment. ${ }^{43}$ When the number of covariates is relatively large in relation to the number of observations, there is a considerable risk of overfitting (i.e., the model estimates are not generalizable to other, similar, datasets). Overfitting is also of concern in the 2SLS context, as the predicted probability of EHNA (first stage) is used as a covariate in the second stage. To reduce the risk of overfitting, we used the Least Absolute Shrinkage and Selection Operator (Lasso) developed by Tibshirani (1996) to select relevant covariates in a data-driven way. The Lasso attempts to select covariates in such a way that the resulting model strikes a balance between high performance and parsimony. It achieves this through shrinkage, in which coefficients are penalized to shrink them towards zero. Coefficients belonging to irrelevant covariates are shrunk stronger towards zero. Estimates for the coefficients are found by minimizing the sum of the squared residuals plus a penalty term on the sum of the absolute values of the coefficients:

$\hat{\beta}=\arg \min _{\beta}\left\{\left(y-x^{T} \beta\right)^{2}+\Phi\|\beta\|_{1}\right\}$

The penalty term restricts the size of the model. The penalty parameter $\varphi$ determines the severity of the penalization. An advantage of the Lasso, compared to, for instance, ridge regression, is that it often shrinks coefficients exactly to zero. This means that the Lasso can be used to select the most relevant variables.

We followed the approach discussed by Belloni et al. (2014), who adopted the Lasso in a 2SLS context. Their approach (see Belloni et al., 2012) differs somewhat from the standard Lasso in that it introduces penalty loadings next to the overall penalty $\varphi$ in the target function:

$$
\hat{\beta}=\arg \min _{\beta}\left\{\left(y-x^{T} \beta\right)^{2}+\frac{\varphi}{n}\|A \beta\|_{1}\right\},
$$

where $A$ is a $k \times k$ diagonal matrix, and where the $k^{t h}$ diagonal element $A_{k k}$ is a penalty loading that corresponds to the $k^{t h}$ regression coefficient $\beta_{k}$. In other words, each regression coefficient is penalized differently, to deal with potential heteroscedasticity in the covariates. Belloni et al. (2012) suggest a method to estimate the coefficient-specific penalty loadings in $A$ in a data-driven way, such that the loadings are asymptotically valid, even under nonGaussian and heteroscedastic errors. They found that using this version of Lasso in combination with 2SLS leads to considerable improvement in the precision of the LATE estimate.

Following the approach for applying the Lasso in a 2SLS context suggested by Belloni et al. (2014), we ran the Lasso separately for three equations: first to select the variables correlated to the leniency score, second the eligibility decision, and third the outcome variable. We then ran a 2SLS regression using all variables with non-zero coefficients in at least one of these equations as covariates.

\footnotetext{
${ }^{43}$ Specifically, we added the categories of the International Shortlist for Hospital Morbidity Tabulation (ISHMT) and all ATC level 4 codes to the set of potential covariates.
} 